
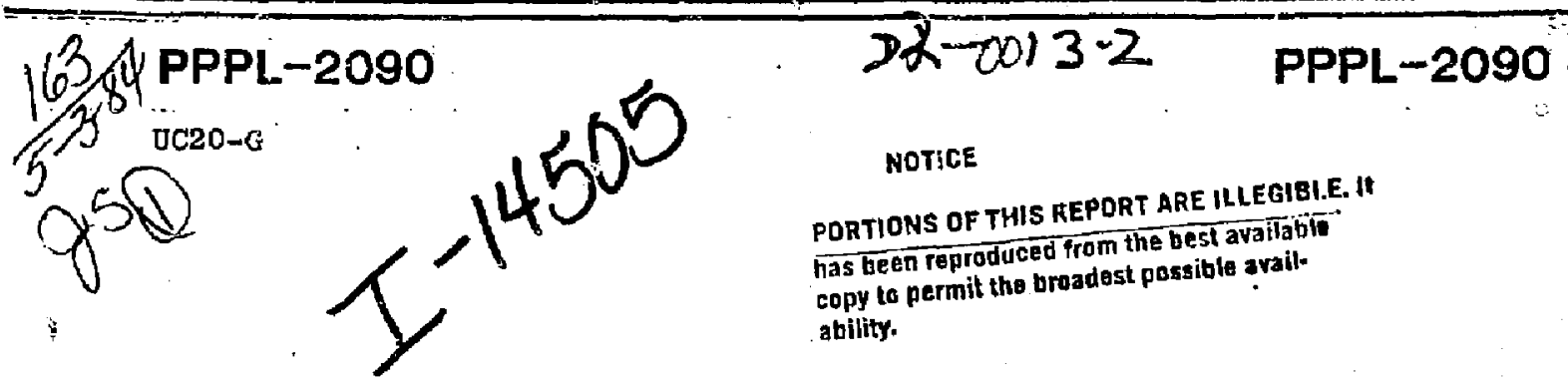

MED STABILITY PROPERTIES OF BEAR-SHADFD TOKAMAKS

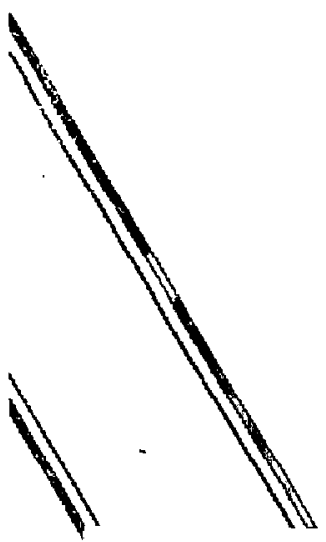

By

PPPL -2090

DE\&4 010753

R.C. Grimm, M.S. Chance, A.M.M. Toda, J. Man1ckam, M. Okabayashi T.M. Tang, R,L. Dewar, H. Fishman, S.L. Wendelsohn, D.A. Monticello, M.T. Phillips, and $K$. Reusch

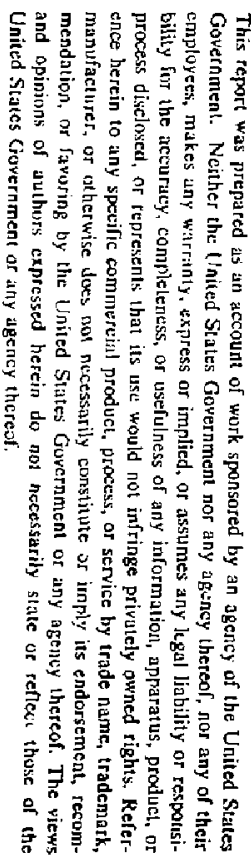

MARCH 1984
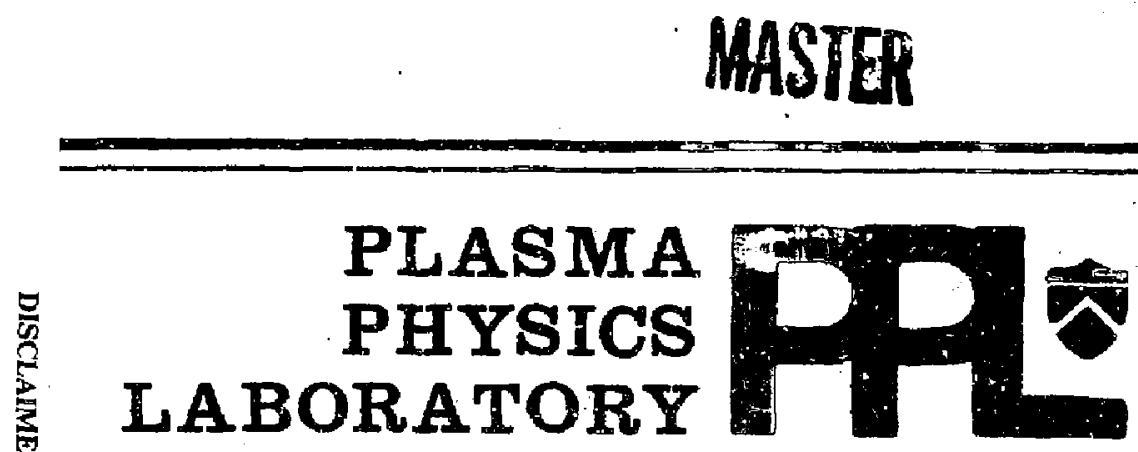

PRINCETON UNIVERSITY PRINCETON, NEW JERSEY

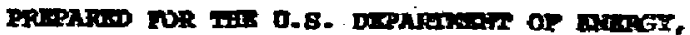

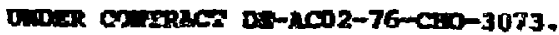




\section{MHD STAEILITY PROPERTIES OF BEAN-SHAPED TOKAMAKS}

R.C. Grimm, M.S. Chance, A.M,M. Todd," J. Manickam, M. Okabayashl, W.M. Tang, R.L. Dewat, "H. Fishman, S. L. Mendelsohn," D.A. Monticello, M. W, Phillips, " and M. Reugch plasma Physios Laboratory, Princeton University P.O. EOX 451 Princeton, New Jersey 08544

\section{ABSTRACT}

A study of the MHD stability properties of bean-shaped tokamak plasmas is presented. For ballooning modes, while increased indentation gives larger $A$ stable configurations, tile existence and accessibility of the second stable region is sensitive to the pressure and safety factor profiles. The second stable region appears at lower B values for large aspect ratio and moderately high q-values. Finite-Larmor-radius (FLR) kinetic effects can significantly improve the stabillty properties. For low $q$ ( $\$ 1)$ operaticn, long wavelength $(\pi \sim 2,3)$ internal pressure driven modes occur at modest $\mathrm{R}_{\mathrm{p}}$ values and accessibility to higher $g$ operation is unlikely. Indentation modifies the nature of the usually vertical axisymetric instability, but the moti can be passively stabilized by placing highly conducting plates near to the tips of the plasma bean. At constant $q$, indentation has a stabilizing effect on tearing modes.

\footnotetext{
* Permanent address: Gruman Aerospace Corporation, 105 College Road East, Princeton, w.J. OB540

'Permanent address: Research School of Physical Sciences, Australian National University, Canberra, Australia
}

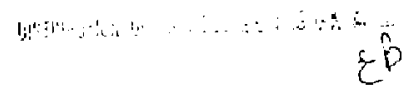




\section{INTROOUCTION}

Several large tokamak experiments $[1,2]$ have recently reached A-values near to the minlmum required for tokamak fusion reactors. While these encouraging results are consistent with theoretical MHD stability analyses, they are close to the lifits expected for pressure driven modeg. Indeed, the comparison of theory and experiment for the B-saturation mechanisms associated with resistive ballooning modes [3] and with the fishbone-internal kink mode [4] indicates that such MHD models should be considered seriously. The deterioration in confinement with increasing $f$ adds incentive to the search' for configurations with improved stability properties, since these would reduce the risks assoclated with the deslgn of ignition experiments, improve the flexibility of design tradeoff studies for future reactors, and may even permit the consideration of advanced fuel fusion reactors.

Detailed numerical parameter and B-optimization studies have shown that, for modestly elongated plasmas, operation at very small abpect ratio $(\mathrm{R} / \mathrm{a}$ 2.5) and moderately law q offers one possible approach to higher stable $\beta$ tokamak configurations $[5,6,7]$. At the present time, this is the conventional approach to inoreasing $\theta$, and experlments to take advantage of this scaling will come into operation in the near future [B]. Small aspect ratio tokamals, however, present numerous technica:- difficulties as power reactors, and alternative approzohes, valid at larger aspect Iatlo, are considered attractive. Thls issue 18 one of the motivations for this work.

There are at least two basic effects, strong magnetic shear and magnetic well stabilization, which can be explolted to pruvide enhanced stability, Increased shear can be realized by poloidal cross-sectional shaping and is already partly responsible for the improved \& values of Dee-shaped tokamak conflgurations over those with circular or elliptical cross sections. That further improvement can be ubtalned by enhancing the weighting of field lines 
in good curvature regions by indenting the inboard small major radius side of a tokamak, has been sugge日ted in earller studleg $[6,7,9,10,11]$. However, a detailed analysis of the consequences of thls bean shaping on ballooning and other global MHD Instabilitles has not, until recently, been undertaken. The second effect, which is associated with the large outwards equilibrium Shafranov shift which occurs at large $\beta$, has also attracted considerable attention $[12,13]$. While a localized analygis clearly supports the concept of a second stable ballooning reglme at large $\beta$, detailed numerical calculations $[14,15]$ have shown that it is difficult to gain access to such regimes on all the plasma cross-sectional magnetic surfaces simultaneously, except at very large aspect ratios or at high q. Hence, it appeared that such high-p reglons would be difficult to achieve practically.

That a combination of these two effects could provide for a ballooning mode stable path to very high $A$ values in medium aspect ratio, slightly elongated, tokamak plasmas, was reported recertly by Chance et al. [16]. Studies of the internal kink mode [17] in bean-shaped plasmas, indicating the possibility of complete stablity, further increased interest in these configurations. As a result, the Princeton PDX experiment is currently being modified to enable a study of some of these advantages. As part of the effort associated with this reconfiguration, and also because of the possible 1mplications for future devices, parameter studies of some of the more important MHD modes in bean-shaped plasmas have been carried out, and are the subject of this work.

In the next section we review briefly some of the standard techniques used in this work, describe the equilibrium conflgurations, and discuss some of the Iimitations of the present study. The results of a localized ballooning analysis are presented in Sec. 3. We concentrare primarily on the 
effects of the safety factor profile and the scaling with aspect ratio, but also included are studies of variation and optimization of the pressure profile, the effect of elongation and of the stabilizing influence of finite Larmor radius effects. In Sec, 4 we consfder geveral long wavelength vHD morles. The axisymetric (vertical) instability is particularly interesting because it occurs with no $\beta$ threshold and must be stabilized in order to create and sustain a bean-shaped plasma. Since the $n=1$ 1nternal kink rode is stabilized by indentation, it is also of interest to study other low $n$ internal modes for $q_{0} \leqslant 1$ as possible candidates for "fishbone" activity. A study of the $n=1$ tearing mode $1 n$ low $B$, bean-shaped plagmas is included since it illustrates that strong indentation can reduce other ingtability driviny mechanisms, in addition to those assoclated with the plasma pressure. A discussion of the main results and some implications for the Princeton Beta Experiment (PBX) device are given in Sec. 5.

\section{EQUILIBRIUM AND STABILITY METHODOLOGY}

Our present understanding of $\beta-11$ miting processes in tokamaks is based heavily on ideal, single fluld, Mto equilibrium, and stability analyses. The simple MHD model has the virtue of being well understood, both qualitatively and quantitatively, and it is generally accepted that only configurations which have favorable properties in this model are likely to be viable candidates for sextous consideration as future reactors. Because of the complexity of the equations involved, detatied analysis can only be carried out numerically. The calculations presented here are similar to those carried out in support of the degign of most present day tokamaks and for several future reactor deglgng.

Carrying out an MHD analygis requires the calculation of suitable 
equilibrium solutions of the Grad-Shafranov equation, In which the plasma is modelled as an infinitely conducting fluid gurrounded by a vacuum region and supported by an external field $[18]$. This $1 \mathrm{~s}$ called a free-boundary equilibrium. For practical application, it is necessary to specify the external field in considerable detail in order to determine the shape of the plasma surface. Alternatively, one can prescribe a reasonable shape for the plasma surface, solve the fixed-boundary equilibrim problem with an infinitely conducting shell on this surface, and leave the necessary external equilibrium field as a separate calculation. This is the approach most convenient for theoretical parameter studies and is the one folloted for the majortty of calculations presented here. We define the plasma surface by [16].

$$
\begin{aligned}
& x(\theta)=\tilde{x}+p \cos t, \\
& Z(\theta)=E_{\rho} \text { sint, }
\end{aligned}
$$

where $\rho=1+B \cos \theta, t=C \sin \theta, 0 \leq \theta \leq 2 \pi$. An illustration is given in Fig. 1, with $B=0.6, C=97^{\circ}$, and $E=0.895$. To quantify the effects of indentation $1 \equiv \mathrm{d} / 2 \mathrm{a}$, we vary $\tilde{x}, \mathrm{E}$, and $\mathrm{C}$ in Eq. (1) so that the elongation (b/a) and the aspect ratio $(R / a)$ remain constant.

To specify an equilibrium, two surface functions mus ${ }^{2}$ be given. We take

$$
p(\psi)=p_{0}\left[1-\left(\frac{\phi}{\Delta \psi}\right)^{\alpha}\right]^{\beta},
$$

with $\Delta \psi$ the poloidal flux within the plasma. Most of the calculations reportad here have $\alpha=\beta=2$, resulting in flat profiles aear the magnetic 
axis $\{\psi=0)$ and plasta edge $(\psi=\Delta \phi)$. For the second surface function, we apecify the safety factor profile,

$$
q\left(\frac{\phi}{\Delta \phi}\right)=\prod_{1=0}^{3} q_{1}\left(\frac{\phi}{\Delta \phi}\right)^{1},
$$

with the coefficients, $q_{1}$, chosen to give prescribed values for $q$ and its first derivative at the magnetic axis and at the plasma surface. Characterizing each equilibrium $1 \mathrm{~g}$ an average $A$ value which we define as $\langle\beta\rangle \equiv$ $2 \mu_{0} J p d v / T^{2} d v$

When the equilibrium problem is posed as above, the toroldal plasma current is determined self-conslatently from the pressure balance equation and cannot be separately adjusted. In Fig* 2, we 11lustrate some of the features of the current profiles associated with the cholce $q(0)=1.03, q(1)=4.2$, $q^{\prime}(0)=0.84, q^{\prime}(1)=9.0$. Comparison of Fig. $2(a)$, and Fig. $2(b)$ indicateg the variation with indentation at low $<\beta$ ( 0.0 .18$)$, while F1g. 2(b) and Fig. $2(c)(c g)$ a 10s) lilugtrate the effect of varying $B$ at similar indentation. since the current profile cannot be measured directly in tokamak experiments, one can really only speculate about whether or not these profiles are realistic. At low $B$, indentation primarily modiftes the current profile near the plasma surface, for $q$ - consexved sequences such as these, and the bulk current profile is relatively unaffected. At very high $A$ valueg, the current profiles become peaked near the plasme edge and additional understanding of plasma evolution is required befice one can judge whether ouch configurations are achievable without auxiliary (ncn-ohmic) current drive schemes. It has also been suggested [19] that the proximity of the beparatrix surface in strongly indented plasmas may act to keep the safety factor profile monotonic near the plasma edge, avoiding the anomaloug current penetration usually 
attributed to field line reconnection associated whth resistive double tearing modes. IE this should be the case, the ohmic currents may penetrate on the plasma skin time and current profiles, as in Fig 2 ( $\sigma_{i}$, might arise naturally. The MFo stability of the equilibria generated was studied with a variety of numerical codes. For localized ldeal and resiative Interchange modes, the quantities $D_{I}, D_{R}$ were evaluated on each of the equilibrium flux surfaces \{20). Short wavelength modes were studied by solving the infinite-n ballooning equation [21] (in the incompressible limit), and a critical-n value was obtained by applying the quantization condition to the wKB solution [22]. This analysis was carried out on every third flux surfare, and the equilibrium was considexed bellooning stable only if it was stable on each of the surfaces tested. For long wavelength modes $(n=0-3)$, the Pest 2 code [23) was used to determine the marginal stability bounfaries, and PEST 1 [24] was run to illustrate the nature of the eigenfunction. The resistive PEST [25] code was used to study tearing modes.

During the course of the parameter studies reported in the next sections, more than a thousand equilibria were generated and several thousand stability calculations were carried out. Since it was obviously not feasible to monitor the numerical accuracy of each case, convergence studies were performed on representative cases, and the various nunerical parameters in these codes were then set to values adequate to resolve those situations. Convergence studies of the equilibria and ballooning results were performed at modest indentation, with $\langle\beta\rangle \sim 158$, and the results were compared for several different coordinate systems. Good agreement between the critical-n estimates from the ballooning code and PEST 2 helped to establish an adequate number of expansion functions for the latter. For most of this work, equilibria were then generated on a 51 $\times 121,\{\psi, \theta\}$ equal arc length mesh; the equilibria were mapped to a $97 \times 128$ 
PEST coordinate mesh for the ballooning otudy and for $n=0$ modes, and to a $200 \times 128$ mesh for the $n=2,3$ internal modes. The finite-n PEST sturles used 100 radial finite elements and 30 Fourier modes. The resistive PEST calculations used up to 400 radial eiements and 20 Fourier nodes.

\section{BALLOONING MODES}

The exlstence of a high- $\beta$, second region of stability to ballooning modes has been predicted by various theoretical analyses. With modest aspect ratio and typical q-profiles $(1 \leq q \leq 2-4$, Chance et al. [16], showed not only that indentation lowers the value of $B$ corresponding to the second stable region, but also that there exists a critical Indentation beyond which no internal ballooning modes exigt, The calculations of this gection were carried out to determine how sensitive the extstence of the second stable region and the critical indentation for accessibility are to a vartation of the various equilibrium parameters. For most of the work the results will be compared to the case studied previously [16], which we shall see was, in many senses, quite optimal. With $q(0)=1.03, q(1)=4.2, q^{\prime}(0)=0.84, q^{\prime}(1)=$ 9.0, $\alpha=2, A=2, \mathrm{R} / \mathrm{a}=4, \mathrm{~b} / \mathrm{a}=1.386$, typical profiles are shown in Fig. 3. The marginal stability diagram for Infinite-n ballooning modes as a function of indentation is reproduced as the dashed curve in Fig. 4.

\subsection{Aspect ratio scaling}

The effect of varying the aspect ratio of the rectangular box containing the bean-shaped plasma is fllustrated in Figs. 4 and 5. In Fig. 4, maxginai gtability curves afe given for two larger aspect ratio devices, in addition to the standard case. At gmall indentations, these results are consistent with previously established results for clrcular plasmas, showing that the lower 
critical- $\beta$ value decreases with aspect ratio. However, we see that the second stable region also sets in at smaller values of $A$ as the aspect ratio is increased. This is particularly noticeable at zero indentation where, for these profiles, only the case for which the aspect ratio equals 10 actually enters the second stable region. The dramatic decrease in the upper critical Br from about 158 at $l=0$ to approximately 58 at $1=0.1$, provides an excellent illustration of the effect of even small bean shaping.

In Fig. 5 we have plotted the marglnal $A$ values, as a function of $\mathrm{R} / \mathrm{a}$ at a fixed indentation $(1=0.304)$, close to the cxitical indentation for complete stability. We see again that hlgher stable $A$ values in the first region are obtained with low aspect ratio. As $R / a$ is decreased, the lower critical < $\beta\rangle$ scales approximately as $(\mathrm{R} / \mathrm{a})^{-3 / 2}$, but in light of the definition of $\langle\beta\rangle$, it is not straightforward to compare this in detail with previous scaling laws for circular or dee-shaped configurations [6]. In the limit of small aspect ratio, however, the second stable region becomes fncreasingly

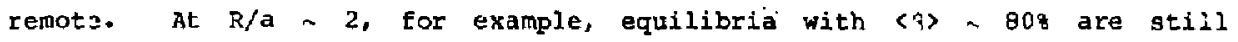
unstable. As the aspect ratio is increasca, the region of instability rapidly shrinks, making it appear more likely that operation above the balioonlng lint should be possible. However, at this fixed value of indentation, the instability region does not vanish, at leagt out to $R / a \sim 20$, which is as far as the present study has been carried. In fact, as seen from Fig. 4, at larger aspect ratio the critical indentation for complete stability at all B is increased, making it necessary to deform the plasma shape more to create an accessible path to the second stable region. Schertes which take advantage of the additional stablization associated with the injection of high energy particles to pass directly through the unstable ballooning rejion are also likely to benefit from operating at larger aspect ratio [26]. 


\subsection{Satety factor saling}

A number of calculations have been peformed to determine the effect of $q(\psi)$ on the standard accessibility curve of Eig. 4. This is lmportant since varying the q-profile within this malel can strongly affect the jesulting current profile.

In Fig. 6 we have repeated the calculetions of the standari case with flatter q-profiles, generated using Eq. (3) with q(1) equal to 2.7 and 3.2 , but keeping $\Delta\left\langle q^{x}(1) / q(1)\right.$ Elxed. This is d model which, in a crude sense, tends to keep the st.laratrix surface at a fixed distance from the olasma eage. At small indentationg, it can be seen that a reduation of the edge q has the effect of removing the second stable region at high $A$. Th1s appears to be a continuous process in which, at $q(1)=3.2$, even the coucept of a critical indentation vanishes. For smaller q(1), while there is a considerable inprovement in A for large indentations, no second stable region appears. Nevertheless, it is a charactexistic of these high-B, bern-shaped equilibria ( $) \geq 108$ ) that the WKB ctltical-n values are quite large $\left(n_{c}>100\right)$, Eor $i \geq 0.2$, and these modes may be stabilized by kinetic effects $[27]$. For $i \leqslant 0.2$ the boundary of the first stable region sades as $\langle\beta\rangle q(1)$ - constant.

The trend ghown in Fig. 6 suggests that Increasing the edge $q$ value above 4.2 sould reduce the critical f for the onset of the second stable region at sinall infentations and this 15 shown in Figs. 7 and 8 . Here are presented the results of a detailed study for the case $q(1)=5.2$, which was carried out over a much wider range of $\beta$ values to gain an undertitanding of the connection between changeg in the equllibrium and the ballooning stability propertles as B is increased. Figure 7 gives the otability boundary for this configuration, while in Fig. B we indicate the regions of the plasma cross section which are 
unstable to balloonlng modes for various values of the indentation.

In discussing these diagrams we concentrate first on the ballooning stability properties of those surfaces contained inside surface 90 of Fig. 8. This Information is shown by the solid lines on both diagrams. Erom Fig. 8 it can be seer that, at small indentation, a broad range of surfaces become unstable at low $B$, centered around the region where $p$ is a maximum (near surface 60). This corresponds to the first critical $A$ boundary for $\langle\beta\rangle=28$ on Fig. 7. As $B$ increases to the second $B$ boundary near 158, the last surfaces to stabilize are nearer to the magnetic axis where the global shear is relatively weak. For configurations with $1 \leqslant 0.4$ this stable region persists until aß八 a 35\%, when ballooning instability again occurs, this time for a range of surfaces closer to the plasma edge. This corresponis 20 the upper stability boundary near $\langle\beta\rangle+40 \%, i \sim 0.2$ : Again this range spreads out, involving surfaces nearer to the plasma centre which had, at low $\beta$, already entered the second stable region. This effect might not have been expected from previous analytic work based on a local perturbation of equilibrium quantities [29], and reflects the signtfleant modifications to the shape of the surfaces as the magnetic axis shifts at very large $B$.

Superimposed on Elg. 7 and 8 (dashed curves) are the modifications to this interpretation if we include the ballooning analysis of those equilibrium surfaces between surface \# 90 and the plasma edge (\#97). Then we find that, at large indentation $(i>0.3)$, equilibria which are stable over the inner 908 of the plasma cross secion become ballooning unstable near the plasma edge and there is no second stable region, although there is a strong improvement in the first stability boundary near $i=0.4$. For $i<0.3$ a second stability region appears; for $0.25 \leqslant i \leq 0.3$ this ends abruptly when ballooning instability occurs near the plasma edge. For $i \leqslant 0.25$ the surface instability 
does not occur and the stability boundary moves up close to 408 . Thus, if we Include the stability properties of gurfaces very close to the plagma surface, we would conclude that the stable regions are confined to lle below the first stability boundary (extended by the dashed curve to $1 \sim 0.5$ ), and ingide the region bounded by the solid line near $1=0.1$ and the dashed curve near $1=$ 0.3. We are unable to reach a firm conclusion about this situation because of uncertainties in the accuracy of the numerical equilibrium calculations near the plasma edge. Since only two numerical equilibrium zones are available for representation of the last $10 \%$ of the plasma cross section (the equilibrium code uses $\phi^{1 / 2}$ as a coordinate), the interpolation on the equilibrium mesh may not be sufficientiy accurate there, although it is much more accurate inside surface \#S?. Considerable effort would be required to improve this resolution. Nevertheless, we have included a discussion of this 1ssue because it illustrates the pitfalls associated with numerical calculations of this type which have often lead to difficulties in comparing studies by different authors [29]. The systematic trend which is seen in these results near the plasma surface is not indicative of large numerical errors and it is likely to persist. If it does, we do not believe the impact on the overall stability properties is significant - the critical $n$ numbers are large, the associated growth rates are small, and small modifications in the profiles near to the edge would most likely remove the offending unstable surfaces, moving the stability boundary back to the solid curve of Fig. 7.

When the solid curve of Fig. 7 is considered together with Fis. 6, we obtain a consistent picture of the effect of increasing q(1). For small q(1) improvements in the maxinum stable $P$ values occur at large values of the indentation. As $q(1)$ is increased, the stability boundary is bent upwards and in towards smallex Indentations, producing afi increasingly large second stable 
region. Our calculations show that there is always a celling to this second stable region, which moves $u p$ as $q(1)$ is raised. (This was not observed previously for the standard (q $=4.2$ ) case, because the calculations we:e not carried to sufficiently hlgh $\beta \cdot]$ while this feature clearly favor, large q(1), the value of the critical indentation for accessibility to this second regton becomes larger - and hence more difficult to achieve practically.

In addition to the strong dependence on the value of $q$ at the plasma boundary, it is also to be expected that the atabilicy proporties should be sensitive to $q$ at the magnetici axis. To illustrate this, we doubled the value of q(0), holding $q(1)$ fixed at 4.2 , thus reduaing the global shear and increasing the connection lengih. As seen in Fig. 9, for the case Ra $=10$ already given in Fig. 4, this has the effect of significantly reducing the critical indentation, which now occurs near $i=0.07$. Neve theless, while the second stable region exists even for b-shaped plasmas ( $=0)$ at this aspect ratio, some indentation is helpful in floding ballooning stable paths from low- $\beta$ configurations.

In addition to separately adjusting the q-profile near the magnetic axis or the plasma surface as done above, it is possible to study the effect of $q$ by scaling the toroidal flejd at constant $B_{p} \equiv 4 \int p d V /\left(\mu_{0} I_{p}^{2}\right)$. For $10 w-B$ cquilibria, or if the adjustment is small, the principal effect is a uniform scaling of qfih, but both $q$ and $q^{\prime}$ can be sigmificantly altered at higher $B$. Figure 10 illugtrates the results obtained by taking each of the set of equilibria used to generate the standard case of Fig. 4 and examining the ballsoning stability after scaling $q(0)$ to values different from 1.03 . As aIready seen in Fig. 9, increaaing q(0) reduces the instability region, making accestibility easier. When $q(0)$ is reduced below, it becomes increasingly difflcult to stabilize internal, pressure-driven modes. As we shall see in sect 
4. long wavelength, $n$, 2,3 modes with broad eigenfunctlons appear in this region of parameter space.

\subsection{Pregbure profile effects}

In the previous bection we have seen tiat the stability properties of beanshaped plasmas can be quite zengltive to the oafety factor proflie. In all of those studios a fixed presaure proflie, $\mathrm{kg}$. (2) with $a=6=2$, was employed. Since this proflie has small values of $P^{\prime}$ near the magnetic axis fwhere the global shear is sma11), one might expect that th would be favorable witis respact to losalized ballnoning modes. An indication of the advantaye of flat presaure profiles has hern geen previously in the gtudy of the stabillration uf the internal kink mollo $[17]$, and, as in that work, we might expect here a gtrong depentence on tire pressure proflie.

In Fig. 11 we illustrate that this is indeed the dage with two separate calculationg. Firgt, we set $a=1, \beta=2$ [so that $\left.p^{\prime} \mid 0\right\} \neq 01$, anr] repeat the stability calculations for the gtandard case. The results are given by the dashed curve. At modegt indentation the first gtebllity boundary ls essentially identical to the standard case, but there is no dramatis improvement at arge infentation, and no evidence of any second stable reglon, even up to $69>$ - 203 with $i=0.35$. Woreover, in that reglon, the wog oritical-f value is gmall $(-3,4)$, and it is therefore unlikely that kinetic effects would provine any signiflant stabilization.

While this result is pessimistic. the fact that the standart cage does possess a second stable region suggests that some optimization sibula be posglife, and it is of interest to determine what shape the presgure profile must adopt to accomplish this. an iterative procedure to carry this out can he developed from the ballooning mode equation. Consider a low $p$ equilibxium at fixed Indentation which 1 in the first stable region to ballooning modeg. Since 
the pressure gradient appears in the infintto-n ballooning equation parametricaliy, it is reasonable to assume that it could be increaged locally on any specific magnetic surface before that particular surface becomes marginajly stable. If these adjustments are carried out, the total average $B$ would be increased. of course, it is necessary to take Into account the fact that these modifications in the presale profile, in turn, lead to a new toroldal equilibrium, which must be computed in order to make the optimization selfconsistent. If, at any stage in the iteration between the equilibrium calculation and the solution of the ballooning equation an instabllity appears, we reduce $p^{\prime}$ on unstable surfaces to the marginally stable values. Following this procedure for fixed indentation and safety factor profile, efther the seguence of equilibria generated will excend to arbitrarily high , or. the process will converge to a pressure profile which is marginally stable to a ballooning analysis on each magnetic surface. This profile then produces the optimal $\beta$.

The results of carrying out such a procedure for five values of i, are also shown in Flg, 11. We see, that, with modest indentation, significant improvement in the first region of stability can be achieved over both of the fixed pressure prefiles discussed earlier. In Fig. 12, optimized pressure profiles are shown for geveral values of indentation. By comparison with the flat pressure profiles of the standard case, we see that as the cross gection is indented the gains have been made by increaging the pressure gradient near to the plasma surface, where the effective indentation of the magnetic surfaces and henge weighting of the good curvature region is larger. In addition to the improvement at small Indentation, these calculations demonstrate a smaller critical indentation which must be provided in order to reach the second stable region. Indeed calculations at $i=0.2$ with optimized pressure profileg remove the ingtability region of the 
standard case. However, we have not yet devised a successful strategy for minimizing the gecond stable reglon marginal stabllity boundary at small indentations. This aspect will be the subject of further studies.

\subsection{Effect of plasma elongation}

In previous studies it has been established that increasing the ellipticity of the plasma surface can 1mprove the stability to internal pressure-driven modes [5]. These results apply to the critical $\beta$ cosresponding to the stability boundary of the first stable region, and it is of Interest to extend this study to configurations exhlbiting the second stable region.

The results of such a study are given in Fig. 13. Here we have considered three sequences of equilibria with different values of elongation, b/a (see Fig. 1), but with identical pressure $(\alpha=h=2)$ and safety factor profiles $q(1)=2.7$ (as in Eig. 6), $i=0.25$, and $R / a=3$. For each case we have plotted the WKB critical-n value versus average $\beta$. As $B$ is increaged, baliooning modes first appear with $\mathrm{n}_{\mathrm{C}}=\infty$, corresponding to the stability boundary of the first stable region. At low B these results illustrate that elongation increases the possible stable A values. Above the marginal a value, increasing the pressure lowers the value of $n$ for which instability occurs, with Ionger wavelengin modes becoming unstable. If the equilibrium configuration is to display a second stable fegion, $n_{\epsilon}$ must eventually become infinite again as $B$ is raiged. For the sequences stuaies here, only the cage $b / a=1$ has this property, entering a gecond stable region at $\langle\beta\rangle \simeq 10 \%$. At higher values of $\beta$ the configuration becomes uratable again near the plasma surface, a feature stmilar to that discusged with respect to Fig. 7. The other configurations, with elongated boundarles, do not display a second stable region, although tie results for the standard case(b/a = 1.4$)$ indicate a strong improvement in stability for $\langle B\rangle\rangle$ 15\%, and it could be 
expected that FLR effects would stabilize these modes. However, from the results for the $b / a=1.7$ case, it can be clearly seen that vertically elongating beanshaped plasmas does not enable easier access to the second gtable region. on the other hand, these results suggest that reducing b/a below 1 should lead to additional reduction in the $B$ value corresponaing to the second stable region, and, therefore, that some indentation could allow accessibility to the second stable region exhibited by tokamaks with horizontally elongated cross sections $[30]$

\subsection{Finite inn Larmor radius stabilization}

It has been estabilshed that for large values of $n$, kinetic modifications to the MHD analysis of internal ballooning modes can be very 1mportant [27]. In particular, the stabilizing finite gyroradius contribution from ion diamagnetic drifts acts directly againgt the interchange driving mechanism and becomes significant when $k_{1}^{2} \rho_{i}^{2}$ is comparable to $L_{p} / L_{k}$. Here, $\rho_{i}$ is the ion gyroradius and $L_{p}$ and $L_{K}$ are the respective scale lengths for the pressure gradient and fleldI.ine curvature. Since the worst ideal MHD cases exist for the smallest value of $L_{p^{\prime}}$ substantial modifications can result even for small values of $k_{L} p^{*}$ Previous calculations have shown that when both the radially nonlocal (finite-n) corrections and the fintte gyroradius effects are simultaneously included, the resultant estimates of critical B can be significantly more optimistic for specific equilibria [27]. Hence, an analysis of this type for bean-shaped tokamk equilibria is of considerable interest.

We have applied the procedure described in Ref. [27] to representative bean-shaped tokamak equtlibria, and found that the kinetic effects can lead to significantly more optimistic f-criteria. This is illustrated in Fig. 14 where the kinetically modified stability boundaries are shown as solid 
curves. For typical parameters, the actual values of $k_{1} p_{i}$ in these calculations remain well below unity.

In this analysis attention was focused on kinetic modifj.cations due to the fon diamagnetlc drift terl, since thls factor alone directly influences the interchange driving mechanism of ideal MHD ballooning modes. However, other kinetic effects, such as wave particle resonances and trapped particle dynamics, can also be important. In particular, collisional and collisionless dissipative processes can destabilize both the arift and shear Alfven waves leading to residual growth rates on the drift wave time scale. Here again the dominant kinetic modes or microinstabilities are strongly influenced by curvature effects. Since bean-shaped tokamak equilibxia generally exhibit more favorable curvature froperties, it is likely that microinstabilities will also be favorabiy influenced. These effects will be investigated in future studies of bean-shaped configurations.

\section{LONG WAVELENGTH MHD MODES}

In addition to a study of internal ballooning modes, information ajout the nature of the eigenfungtions of large scale instabilitieg, and about instabilities when the plasma is surrounded by a varulsm region [externa] modes), is needed in order to assess the overall stability properties of a tokamak configuration. Previous work on the $n=1$ mode has shown that the internal kink can be stabilized by indentation, while at finite $\beta$ and indentation, stability to the external kink depends on wall atabilization [17]. In this section, we consider several additional classes of possible ingtability, each of which should have some impliaation for bean-shaped tokamak experiments. 


\section{1 Axigymmetrio $(n=0)$ modes}

It is well known that the simple ideal mHD model of an infinitely conducting, nonclrcular, cross-sectional plasma surrounded by a vacuum region can be ungtable to axisymetrla $\left\langle\partial_{\phi}=0\right)$ motions. If the cross section is vertically elongated, the ungtable motion is primarily a rigid vertical shift, while a horizontally flattened ghape is ungtable to translation in the midplane. Such motions can be passively stabllized on ldeal MHD time scales by the presence of nearby conductors, where eddy currents are generated which oppose the rotion. It $1 s$ of interest to determine where to place such conductors most effectively to aid the experiment design. To do this, we have studied the $n=0$ stability of a typical bean-shaped plasma using various versions of the PEST ccde, whth vacuum boundary conditions approximating different conductor locations. We consider a $\langle\beta\rangle=38$ equilibrium with $i=$ $0.3, q(a)=0.84, q(1)=3.7, R / a=3.3$, and $b / a=1.52$. The pressure and poloidal current profiles used are sinilax to those obtained from Thomson scattering and magnetic flux data in typical PDX shots. The equilibrium was cormuted as a free-boundary calculation using a specific external coil set (Fig. 25) so that the plasma surface does not conform exactly to Eq. (1).

In Figs. 15 and 16 we iliustrate the effectiveness of moving a p-shaped confucting wall (see Fłg. 1) closer to the plasma surface. without a conducting shell (Fig. 15), we can see that the plasma displacement conbines a nearly rigid vertical shift with a circular, sliding component which follows the equilibxim flux contours in the indented region of the cross section. As the wall is moved unfformly closer (Fig. 16), it first stabilizes the vertical shift component, go that the instability takes on the form of sliding notion towards the tip of the bean, with graller growth rate. Since, in this model, the most effective stabilization comes from placing a conductor perpendicular 
to the displacement of a constant Elux surface, it is clear that it is the proximity of the conducting surface near the tip of the bean which is most important at this stage. The instability becomes marginal when $B=A w / A-1$ 0.65

Further investigation of the stabilizing contribution from the region in thar the tips of the bean is imporsant for the PBX experiment, aluce the conducting wall can only be located there, in practice, because the larger major radius region must be kept free to accommudate the planned range of incented plasmas. Such a partial wall was simulated by modifying the definition of the wall lodation in the PEST code to allow certain bections of the wall to be moved out to a large distance from the plasma. As illustrated in Fig. 17a, the stabilizing effect of discrete conducting plates can then be described by two parameters - the length of the nearby sect an of the wall and the distance of this section to the plagma surface. Calculations iave been performed to determlne the dependence on both of these quantities. As an example, Fig. I7b showg the normalized growth rate versus the wall distance, for the section indicated in Fig. 17a. Stablitty occurs when $B$ o.3. giving a wall separation for the FBX experiment of 9-10 cms.

While an idealized calculation such as this is essential to enable positional control on the extremely fast ideal MHD time scale, it is important to appreciate that, for time scales characteristic of the resistive skin times of the wall or plasma, Inatability will usually still occur as the stabllizing eddy currents reaistively decay. The design of a sultable active feedback system, which takes lato account the resistive plasma dynamics, is a crit1cal aspect of any tokamak experiment where non circular, cross-sectional shaping is to be carried out by external poloidal field programming. 
4.2 Low $n$ internal modes with $q(0)<1$

Most tokamaks operate with $q(0)<1$. While on slow resistive MHD time scales the dunamics of low- $\beta$ discharges are determined by resistive relaxation inside the $q=1$ surface, at higher 8 the stability to pressure driven mode日 with $\mathrm{q}(0)<1$ may dominate the plasma behavior, especially if long wavelength instabilities are excited. Such a possibility is suggested by the calculations presented in Fig. 10, whlch showed that the stability properties deteriorated strongly when $q(0)$ was reduced. Since the Internal $n=1 \mathrm{klnk}$ has been shown to be strongly stabilized by 1ndentation, it is natural to consider the behavior of other low $n$ modes at low $q(0)$.

Figures 18 and 20 present the results of a set of calculations for internal $n=2,3$ modes carried out in an identical fashion to the internal kink studies of Ref. 15, using the PEST 2 code. Fot three different values of indentation, each member of a sequence of equilibria with parameters of the standard case of 3.1 were scaled, at constant $B_{p}$, to generate sets of equilibria with different $q(0)$. Testing the stab1lity of these permits ore to construct marginal stability curves in the $\beta_{p}$ vs $q(0)$ plane. Both figures show that at fintte $B$ these long wavelength modes set in at modest values of ${ }^{9}$ over a range of values of $q(0)$, and present a significant limitation to reaching high-B configurations.

For the $\Omega=2$ mode of Fig. 18, instability sets in with $B \Rightarrow 0$ at the Mercier limlt, $q(0)=0.5$, and the most unstable mode is localized near the magnetic axis and dominated by the $m=2$ poloidal component. Configurations with $q(0)>0.5$ are stable at low $\beta_{p}$, but as $\beta_{p}$ is inoreased, a stability threshold appears. Without indentation this threshold is insensitive to $q(0)$ for values $\leqslant 0.9$, but rises quite rapidiy near $q(0)=1$. For both bean-shaped conflgurations the threshold inoreases smoothly ar $q(0)$ approaches 1 . In that 
linit $1 t$ is interesting to note that the $\theta_{p}$ linit decreases with indentation, a result which can also be seen in the $n=$ ballooning linits ghown in Fig. 70 with $q(0)=0.8$ or 0.9 . Figure 19 illustrates the instability elgenfunction of a typical case $\left[q(0)=0.7, \beta_{p}=3.74,1=0.185\right] . A B q(0)$ is increased from 0.5 to 1.0 , the modes become nonlocalized in 4 . with poloidal structure involving masy Fourier harmonics, typlcal of ballooning modes.

Far the $n=3$ mode, shown in Fig. 20, the piature is very slmilar. It differs from the $n=2$ case primarily in the tendency for additional localized modes to set in at low ${ }_{p}$ near the $q=2 / 3$ mode rational surface, and in the fact that the threshold is always lower, as expected from ballooning mode theory. Typical eigenfunctions close to the stability boundary for several different values of $q(0)$ are shown in Fig. 21, 1llustrating the poloidal and radial structure of the most unstable modes. Figures $21(a)$ and $21(b)$ show localized interchange modes which would be well described by the Merier griterion. As $A_{\rho}$ and $q(\hat{U})$ are increased, Fig. $21(c)$ and $2 f(d)$ illustrate that the modes becone nonlocalized, with poloidal variation involving the coupling of many Fourier harmonics.

In the calculations presented in Figs. 18 and 20 , there 19 no indication of a second stable region for $q(0)<1$, at least for $\langle\beta\rangle \leq 208$. If such a region does exist at ruch larger $\langle\beta\rangle$, the results indicate that it is very unlikely that stable paths exist at low $q(0)$ values. Since the modeg have broad eigenfunctions and exhibit a $\beta$ threshold, they may also be candidatee for driving beam injection instabilities, similar to the fishbone modes presently identified with near perpendicular injection in internal kink unstable, PDX configurations. 


\subsection{Ef fect of indentation on resistive modes}

The majox emphasis in this work on the aspects of bean shaping has been associated with the enhanced atability to ideal MHD modes. It is lseful to consider the effect on resistive MHD modes, and we report here on a study of the $\pi=1$ tearing made carried out uaing the restative PEST code $[25 j$ * This code carries out the complete asymptotic matching procedure for a finite B. axisymmetric, toroldal MHo equilibrium. It computes the growth rate of low $\Omega$ resistive instabilities by solving the boundary layer dispersion relation obtained by matching nurierical solutions of the resistive boundary layer equations [20] around each rational surface to the marglnally stable solutions of the ideal MHD equations between these singular regions.

To illustrate the effect of indentation on the kink driving terms we cunsider two pressureless equilibrium gequences with different values of q(1). In the first sequence we take the safety factor profile of the standard case, $(1.03<q<4.2)$, so that for $n=1$ there are three rational surfaces, and we compute the growth rate of the ungtable resigtive mode. In the second sequence we take a similar piofile to the standard case but with $q(0)=1.1$ and $q(1)=2.9$, so that there is just one cational surface at $q=2$. For this case the stability to the $m=2$ tearing mode 1 s determined by the usual criterion $A_{2}^{\prime}<0$, where $\Delta_{2}$ is the ratio of the small to big $m=2$ poloidal harmonic of the ideal MHD solution across the $q=2$ gurface.

Results for the standard case with a conducting wall on the plasma boundary are shown in Fig. 22. We find that there is only one resistive tearing instability associated with the $q=2$ aurface. This mode is seen to be strongly stabilized by indentation and becomes a damped oscillation for i $\geq 0.2$. With fixed q profile, this stabilization can be understood in terms of a flattening of the equilibrium current profile at the $q=2$ surface as 1 
is increased. While the current gradient usually incresses on the outer rational surfaces, the steepening up there is not sufficlent to drive $n=1$ modes unstable. It may destabilize higher $n$ tearing modes near the plasma surface, although these are rarely seen in tokamak devices and are more difficult to destabilize in a cylindrical model. Such modes would lead to small inagnetic islands near to the plasma edge, anr possibly Jegrade confinement. Additional work is needed to understand this effect in detail. When the conducting wall is moved axay from the plasma surface, the tearing moles can be strongly destabilized. An example of this is shown in Fig. 23 where we have considered the barely stable case, $i=0.186$ (arrow) of Fig. 22. With just a small movement of the wall a piedorinantly $m=2(n=1)$ teaxing mode becomes unstable at the $q=2$ surface. As the wall is moved out near to 0.2 plasma radii, a second tearling mode becomes unstable. Near to the marginal wall position for this mode, it has the structure of ar almost pure $m=3$ tearing mode, centered at the $q=3$ surface. H.s this second mode becomes more unstable, the two modes $(m=2$ and $m=3$ ) $m i x$, each producing islands around both the $q=2$ and 3 surfaces. The $m=3$ component grows most strongly as the wall is moved further out to where the ideal MHD external kink mode is destabilized. With $q(1)=4.2$, this ideal mode $1 \mathrm{~s}$ predominantly m $=$ 5, and it is clearly the coupling of this, through ellipticity, which causes the $m=3$ tearing mone growth rate to increase so rapidly.

For the flatter 9 profile $(1.1<q<2.9)$ we find stabllity to the $n=2$, $\mathbf{n}=$ tearing mode even at zero Indentation (Fig. 24). This is consistent with previous calculationg which show that toroidicity can be strongly stabilizing for low shear tokamak equilibria [25]. As the conducting wall is moved away fron the plagma aurface, the results for an indentation $i * 0.1$ show little vilation until the wall is close to the marginal point for the 
$n=1$ (mostly $m=3$ ) ideal MHD external kink mode, at which point the $m=2$ tearing mode is strongly destabllized (Fig. 24, golid dots). We note in Fig. 24 that with this current profile the wall mugt be very close to stabilize the $n=1$ external kink. Additional studies are needed to understand the effect of plasma current profile on these external ideal MHD modes.

These results suggest that strong indentation and reasonable profile control may provide for some stability againgt the nonlinear tearing phenomena which are believed to be responsible for plasma disruptions. Fully 3D MHD nonlinear codes must be employed to atudy this.

\section{DISCUSSION}

In this work an extensive parame ar survey has been carried out to help evaluate the favorable MHD stability properties of bean-shaped tokamak plasmas. While one mat be careful not to extrapolate such results too far from the parameter space considered, it is possible to draw various conclusions, which may be helpful in indlcating ugeful experiments or in suggesting future research areas.

Much of this work has centered around ballooning modes and an understanding of the second stable ballooning region, which offers many attractive possibilities for future tokamak reactor designs. The results presented here support the previous observation that this region is difficult to find in circular and Dee-shaped tokamak configurations, and that indentation is a critical Eactor.

We have found that the ballooning mole stability properties can be sensitive to equilibriun parameters, especially at high-s values near the second stable region. Variation of the safety factor showed that the second stable region increased as the edge $q$ was raised, although the critical 
indentation needed for accessibility increased also. Faising $q$ at the magnetic axis helped to alleviate this problem. Balloonlng modeg quickly get in as $q$ on-axis was lowered below 1 , removing the second stable region. Variation of the pregaure profile showed that, while this can eliminate the second stable region, it is also possible to enhance otrongly the stability properties, and to reduce the critical indentation needed to reach favorable high-B configurations. Further improventent in the gtability properties was also shown to be possible, since near the stability boundarles the balloonlng modes have very short wavelengths and kinetic effects were found to exert a significant stabilizing influence.

Variation of the aspect ratio has clarified different options for reaching high-B values; operating in the first stable region at small aspect ratio and low $q$, or $i$.. the second region at larger aspect ratios and higher q. Given a favorable scal1ng of confinement time with aspect ratio te.g., Alcator, TFTR and the possibility of avolding resistive lnstabilities through indentation, these results indlcate large aspect ratio (A - 5 - 10) beanshaped tokamaks operating in the second stable region would be interegting reactor candidates. In addition to providing the local shear which improves the stability properties, the indentation strengthens the poloidal field on the outboard side enhancing the confinement propertieg.

While a study of internal ballooning modes gives a good indication of che MHD stability properties at high $A_{1}$ it 15 necesgary to supplentent this work with consideration of current driven modes and calculations which illugtrate the nature of the mogt unstable perturbations. Adiing to the work on external kinks reported before, we exarained the $n=0$ mode, identified the behavior of the ungtable motion, and showed that stability could be achieved by placing conducting plates sufficiently close to the tips of the bean-shaped cross 
section. We briefly constdered the $n=1$ tearing mode and found that indentation may have a stabllizing effect on some resistive instabllities. Finally, we considered the low-n Internal modes with $q(0)<1$, found that these have moderately low $\beta$ threshold values, and that they would most likely prevent reaching second stable regions unless q(o) 1s kept above unity.

In this work we bave attempted to gain gome qualitative understaniing of the effect of indentation on various instabilities in bean-shaped tokamaks. The next relevant project would be to optimlze the configuration. Since we have identified a sensltivity to a number of equilibrium parameters, this should be an interesting task to undertake. Although this sensitivity complicates any analysis, because it makes it difficult to isolate a single, simple physical mechanism to describe the plasma behavior, it nevertheless suggests that there are a variety of possible procedures to achieve stable hiqh-B configurations - many of which allow acressibility to the second stable region. Several of them, such as plasma shaping aud cholce of aspect ratio, are within the scope of present day experimental and engineering techniques. Others, which involve control of the pressure and safety factor profiles, are not. However, they may be feasible in future experiments irvolving, for example, refined $R F$ heating and current drive schemes. At the very least, the studies reported here, which demonstrate the existence of very favarable configurations for a varlety of parameter values, should stimulate theoretical work to improve our understanding and the abllity to model tokamak behavior. optimlzation of the properties illustrated here rely to a large extent on this capability.

With respect to the forthcoming PBs, this work identifies several signtficant issues. Most importantly, the ability to form indented plasmas relies on controlling the axisymetric inatability. While conducting wall 
stabilization can reduce the growth rate from the fast 1deal MrlD time gcale, creating high- $\beta$ beans will degend on designing agtive feedback systems which stabilize motions on the resigtive times characteristic of confinement experiments. This is particularly important gince it is planned to form bean-shaped aross sections by the process of continuous deformation from 3 ow- $\beta$ circular discharges.

A second issue in reaching high-B values involves avolding "flshbones", which have been identifled as a major mechaniom for p-saturation in neutral-beam-heated PDX experiments. While sufficient indentation may increase or eliminate the $B$ threshold assoclated with the internal $\mathrm{n}=1 \mathrm{kink}$ mode, other low-n ballooning modes studied here may bave a similar effect when q(0) drops below 1. Since the calculations presented here did not show any improvement with identation for these modes, they pose a concern for near perpendicular injection. Achtevement of high- $\beta$ values may then depend strongly on the orientation of the infected neutral beam.

If both these difficulties can be overcome experimentally, additional calculations of the sort reported here will be needed to interpret the consequences of ballooning modes and the effect of Indentation. This will clearly be necessary becauge the sensitivity to various parameters, illustrated by this work, makes it probably 1mpossible to predict whether or not a second stable region can be identifled. Onc obvious uncertainty Involves the current profiles associated with the Ideal MHD equilibria employed here. These profiles, obtained by specifying q( $\phi\}$, can be quite different from what 1 s observed in present day, lowm, almost circular, tokamak discharges. Attempts to find the second stable region with more conventiral current profiles have not been successful, and while not entirely conclusive, that suggests that additional profile control would be needed to 
achleve all the favorable aspects of indentation. For the pBx experiment, where such control is not avallable, this may Indicate that achieving second stable states is unlikely, However, ralculations with equilibrium profiles typical of actual data taken from the pDx experiment [1], show that substantial improvements in $\beta$ should be possible with indentation. an example of a high-B equilibrium ( 108 ) with typical parameters for the pgx experiment is shown in Fig. 25. Stability studies have shown that this configuration is

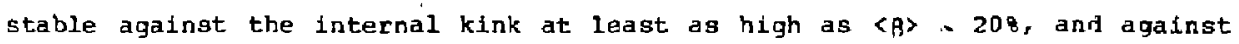
ballooning modes to $\langle B\rangle \sim 98$. These values are in marked contrast with $B_{C}=$ 1.48 (internal kink) and $\beta_{C}=2.78$ (ballooning) previously reported for PDX circular high-R/low-q discharyes.

\section{ACKNOWLEDGENTS}

We gratefully acknowledge the ntmerical support provided by Mr. A. E. Miller. This work has profited from many useful discussions and suggestions with PPL physicists, especially H.P. Furth, S.C. Jardin, F. Perkins, and P.H. Rutherford. We are also Indebted to the many helpful discussions we had with other members of the U.S fusion commanity during a workshop on Bean- Shaped rokamaks held at Princeton, April 1983.

This work supported by U.S. Department of inergy contract \# DE-AC02-76Cro-3073. 


\section{REFERENCES}

[1] D. Johnson, et al., Plasma Phygios and Controlled Nuclear Fusion Research 1982, Vol. 1, IAEA, Vienna, (1983) 1.

[2] K. H. Burre11, et al., Nucl. Fugion 23 (1983) 536.

[3] B. A. Carreras, P. H. Diamond, M. Murakami, J. L. Dunlap, et. al*, Phys. Rev. Lett. 50 (1983) 503 .

[4] K. McGuire, R. Goldatcn, et al., Phys. Rev. Iett. 50 (1983) 991.

[5] A. M. M. Todd, J. Kanickam, M. Okabayashi, M. S. Chance, R. C. GrLmin, J. M. Greene, and J. L. Johnson, Nucl. Fusion 19 (1979) 743.

[6] R, C. Miller and R. W. Moore, Phys, Rev. Latt. 43 11979) 765; L. C. Bernard and R, W. Moore, Phys, Rev. Lett. 46 (1981) 1286.

[7] I. C. Bernard, F. J. Helton, R. W. Moore, and T. N. Todd, Nucl. Fuston $\underline{23}(1983) 1475$.

[a] J. L. Luxon, N. :". Brooks, et al., Proceedings of the 1 ith European Physical society Conference on controlled Fusion and Plasma Physics, Aachen, (1983), Vol 7D, Part 1, 99.

[9] H. P. Furth, J. Killeen, M. W. Fosenbluth, B. Coppi, Plasma ghyoics ana Controlled Nuclear Fusion Research, Vol. 1, IAEA, Vienna, (1966) 103.

[10] C. Mercier in Lectures in Plagma Physics, EURATOM-CEA CEN EUR 5127e, Luxembourg $(1974)$.

[11] L. C. Bernard and R. w. Moore, Phys. Rev. Lett. 46 (1981) 1286.

[12] H. R. Strauss, W. Park, D. A. Monticello, R. B. White, S. C. Jardir, M. S. Chance, A. M. M. Todd, and A. H. Glasser, Nucl. Fubton 20 (1980) 638 .

[13] B. Coppi, A. Ferrelra, J. W.-K. Mark, and J. J. Ramos, Nucl. Fusion 29 (1979) 715

[14] L. Suglyama and J.w.-K. Mark, Phys. Lett. 84A (1981) 123.

[15] D. A. Monticello and s. C. Jaraln (to be published). 
[16] M. S. Chance, S. C: Jardin, and T. Stix, Rhyg. Rev. Lett. 51 (1983) 1963.

[17] J. Manickam, K. C. Grimm, and M. Okabayashi, Phys. Rev. Lett. 51 (1983) 9959.

[18] For example; J. I. Johnson, H. E. Dahled, J. M. Greene, R. C. Grimm, Y. Y. Hsieh, 5. C. Jardin, J. Manickam, M. Okabayashi, R. G. Storer, A. M. M. Todd, D. E. Voss, K. E. Weimer, J, Comput. Phys. 32 (1979) 212.

[19] H. P. Furth, private commanication.

[20] A. H. Glasser, J. M. Greene, and J. I. Johngon, Phys, Fluids 18 (1975) 875.

[21] M. S. Chance, et. al,. in Plasma Plysles and Contrulled Nuclear Fusion Research 1978, Vol. III, IAEA, Vienna, (1979).

[22] R. L. Dewar, J. Manickam, R, C. Grimm, and M. S. Chance, Nucl. Fusion 21 (1981) 493 .

[23] R. C. Grimm, R. I. Dewar, and J. Manickam, J. Comput. Phys. 49 (1983) 94.

[24] R. C. Grimm, J. M. Greene, and J. L. Johnson, Meth. Comput. Phys. $\underline{9}$ (1976) 253.

[25] R. C. Grimm, R. L. Dewar, J. Manickam, S. C. Jardin, A. H. Glasser, and M. S. Chance, in Plasma Physics and Controlled Nuclear Fusion Research 1992, Vol. III, IAEA, Vienna, (1983) 35.

[26] M. N. Rosenbluth, S. T. Tgai, J. W. Van Dam, and M. G. Engquist, phys. Rev. Lett. 51 (1983) 1967.

[27] W. M. Tang, R. L. Dewar, and J. Manickam, Nucl. Fusion 22 (1982) 1079.

[28] J. M. Greene and M. S. Chance, Nucl. Fusion 29 (3981), 453.

[29] F. N. Vabishchevich, L. M. Degtyarev, and S. Yu. Medvedev, Sov, J. Plasma Phys. 9 (1983) 100 .

[30] H. E. Dalhed, R. C. Grimm, and J. L. Johnson, Nucl. Fusion 22 (1982) 883. 

EIG. 8. Showing the regions of the crass section which are balloonting unstable as $\langle g\rangle$ is varted for a set of equilibrium sequences with different indentation. The absctssa is proportional to $\psi^{1 / 2}$.

FIG. 9. Marginal stability boundary for ballooning modes as $q(0)$ is increased, for $R / a=10$, bean-shaped plasmas.

FIG. 10. Ballooning mode stability boundarles showing the variation as g(0) is reduced.

FIG. 1\% Ballooning mode stability boundaries for different pressure profiles; solid line, $\alpha=2$, dotted line, $\alpha=1$, Results of profile optimization are also show.

FIG. 12. Optimized pressure profiles for a Dee-shaped plasma $(1=0)$ and a modestly indented plasma $(i=0.185)$ compared to the standara profile (dashed). $(\hat{\phi} \equiv 1-\psi / \Delta \psi)$.

FIG. 13. Gritical-n value on the most unstable surface as a function of $\langle\beta\rangle$, for $g(0)=1.03, q(1)=2.7, i=0.25, R / a=3$ and three different values of the plasma elongation, b/a.

FIG. 14. Klnetically modified stability boundaries (solid lines) for beanshaped equlibria with $q(1)=3.2$ (as in Fig. 6). Salid (open) dots represent equilibria unstable (stable) to ideal MHD ballooning modes. The FLR modified bountaries are shown for two different particle densitieg. 
FIG. 15. Typical $n=0$, axisymmetric instability for a bean-shaped plasma equilibrium with surrounding vacuus extenaing to infinity.

FIG. 16. Axisymmetric Instability in the presence of a Dee-shaped conducting wall $\{F i g .1)$ at $\mathrm{Aw} / \mathrm{A}=1.65$.

FIG. 17(a) Conducting wall used to simulate the use of axisymetric conducting plates near the bean tips.

EIG. 17(b) Normalized growth rates showing the stabilizing effect of moving conducting walls closer to the plasma surface. Solid dots are for the partial wall of Fig. 17(a), circleg for the solid wall of Fig. 1.

FIG. 18. Stability boundary for 1nternal $\Omega=2$ modes with $q(0)<1$. Results are given for a Dee-shaped plasma $(1=0)$ and two different values of the indentation.

FIG. 19. Displacement vector of a high $\theta, n=2$ internal mode with $q(0)=$ $0.7, g_{p}=3.74$, and $i=0.185$. The elgenfunction has finice radia! extent.

FIG. 20. Stability boundary for internal $n=3$ modes for the same equilibrium configurations as Fig. 18 .

FIG. 21. Radial structure of unstable eigenvectors from PEST 2, for four different values of $\left[q(0), \beta_{p}\right]$ close to the stability boundary for $1=0.3$ in Fig. 20. a) $q(0)=0.31, \beta_{p}=0.72$, b) $q(0)=0.6, g_{p}=$ 1.31, c) $q(0)=0.68, B_{p}=2.23$, and d) $q(0)=0.87, \beta_{p}=3.66$. 
FIG. 22. Effect of 1ndentation on the growth rate of tice $n=1$ tearing mode $\left(n=10^{-6}\right)$ for bean-shaped plasmas with $q(0)=1.03, q(1)=4.2$, $k / a=4, b / a=1.386$. Calculations at values of 1 indicated by the two arrows give damped, stable modes.

FIG. 23. Effect of moving the wall away from the plasma surface on Fig. 22, showing the onset of two registive tearing modes and an ideal kink mode.

EIG. 24. Effect of indentation (npen circles, bottom axis) and wall position, $B$ (dots, top axis), on the $m=2$, $n=1$ tearing mode for equilibria with $q(0)=1.1, q(1)=2.9$.

FIG. 25. Bean-shaped, flux surfaces for a $\langle\beta\rangle=108$ equífibrium in PBx. Also shown are poloidal field coil locations and external conducting stabilizer plates. 


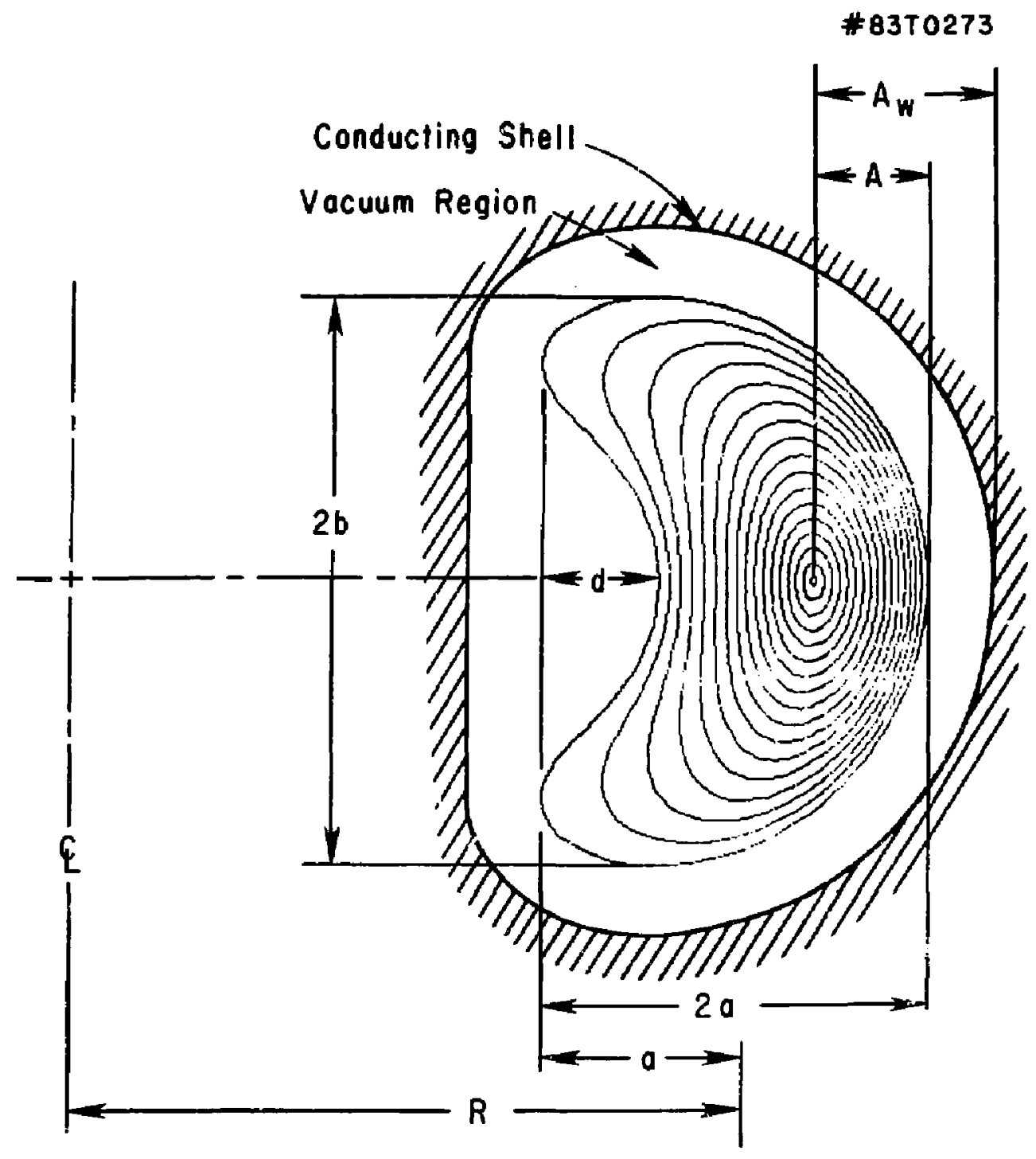

Fig. 1 

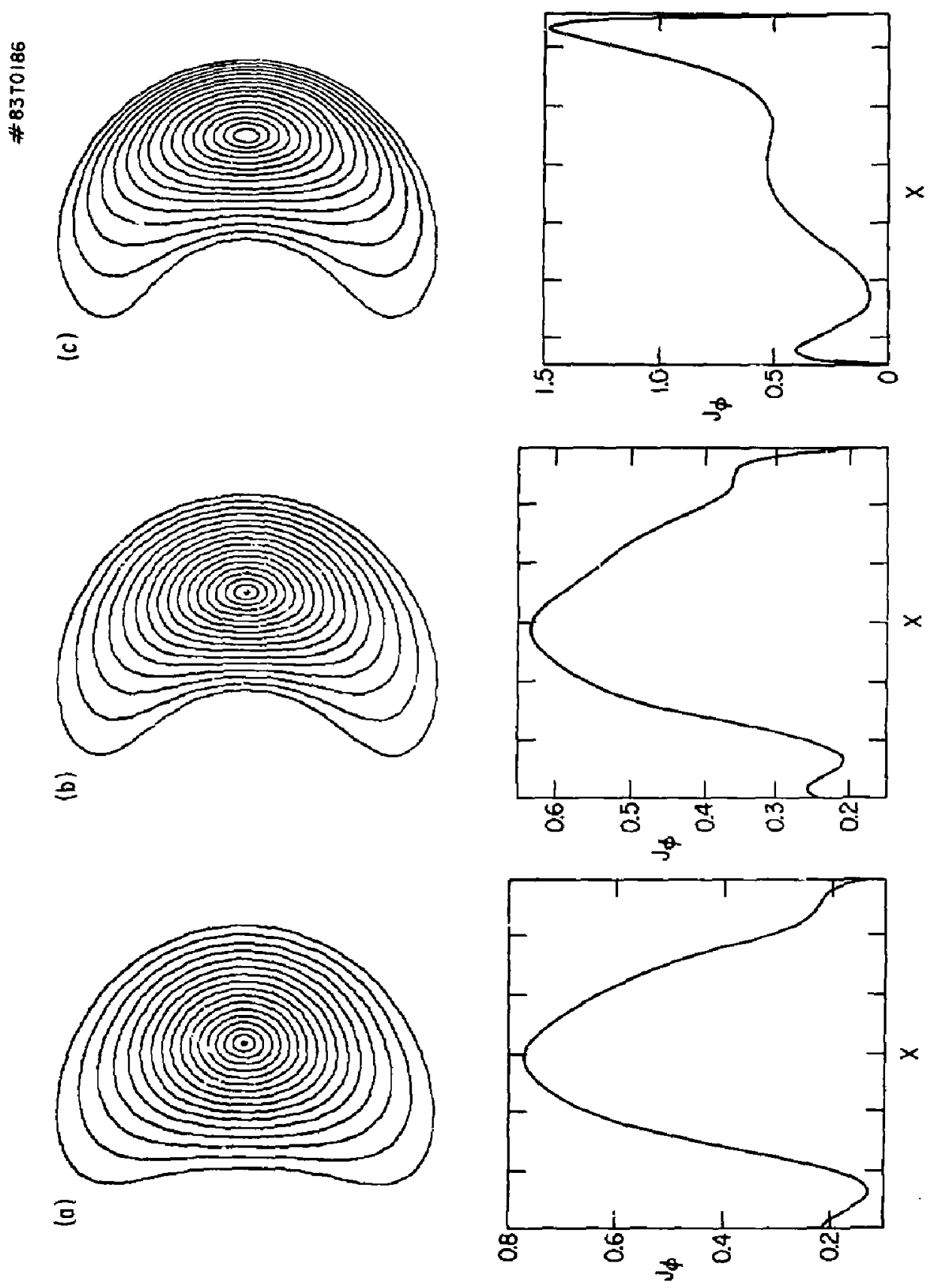
*83T0483

$$
\begin{gathered}
\frac{\text { Profiles }}{\langle\beta\rangle=8.75 \%} \\
i=0.304
\end{gathered}
$$
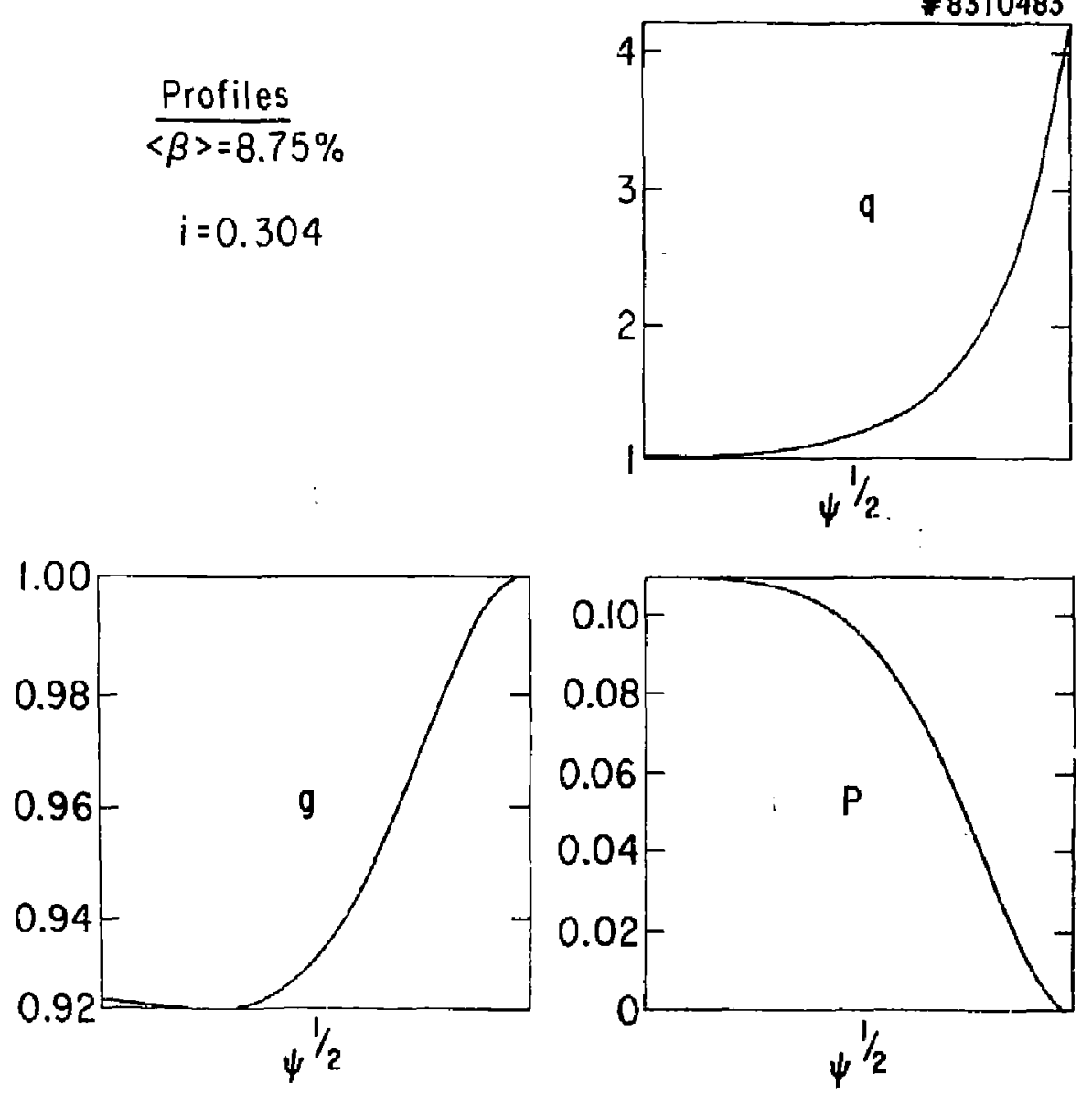

Fig. 3 


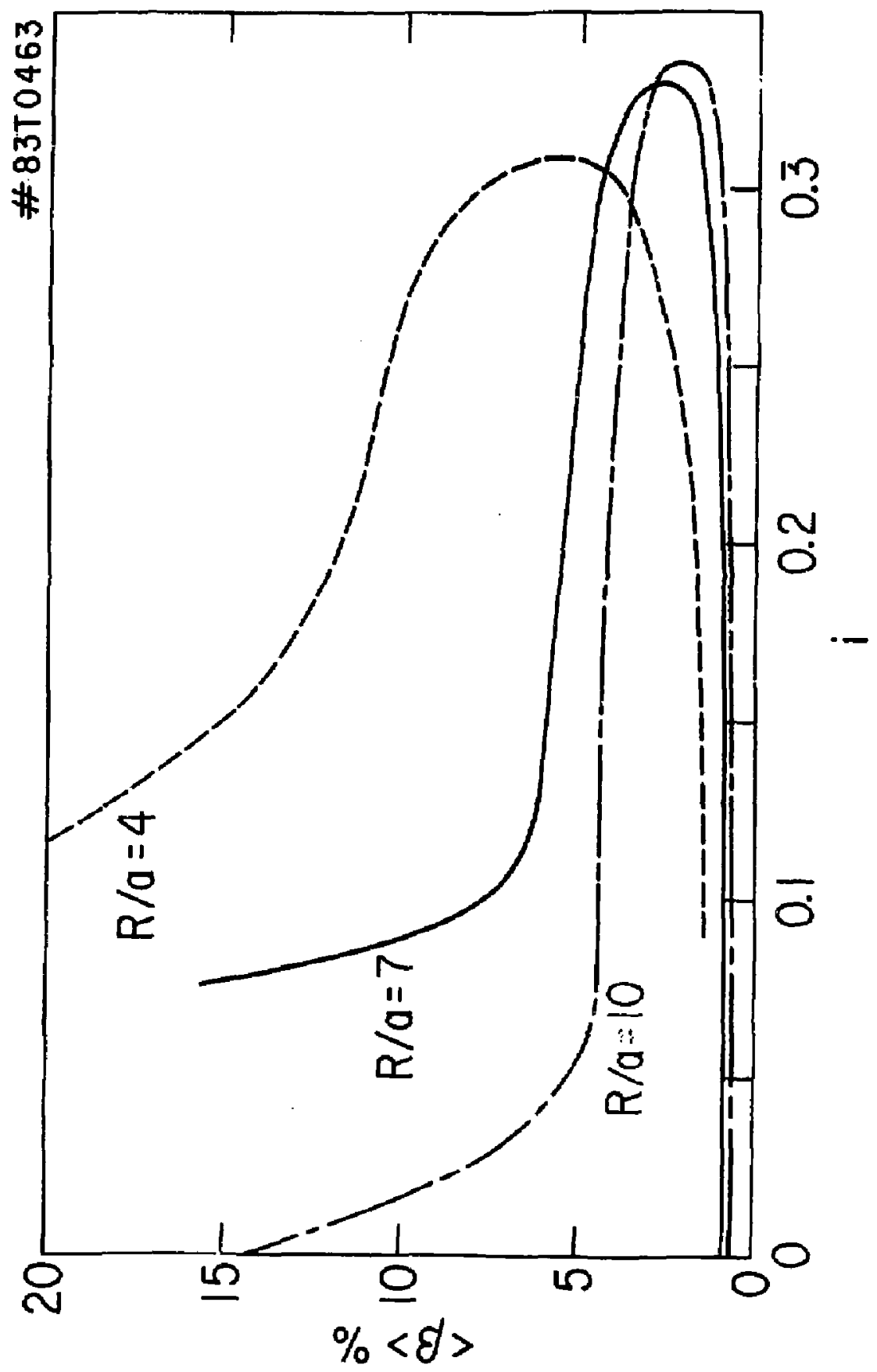




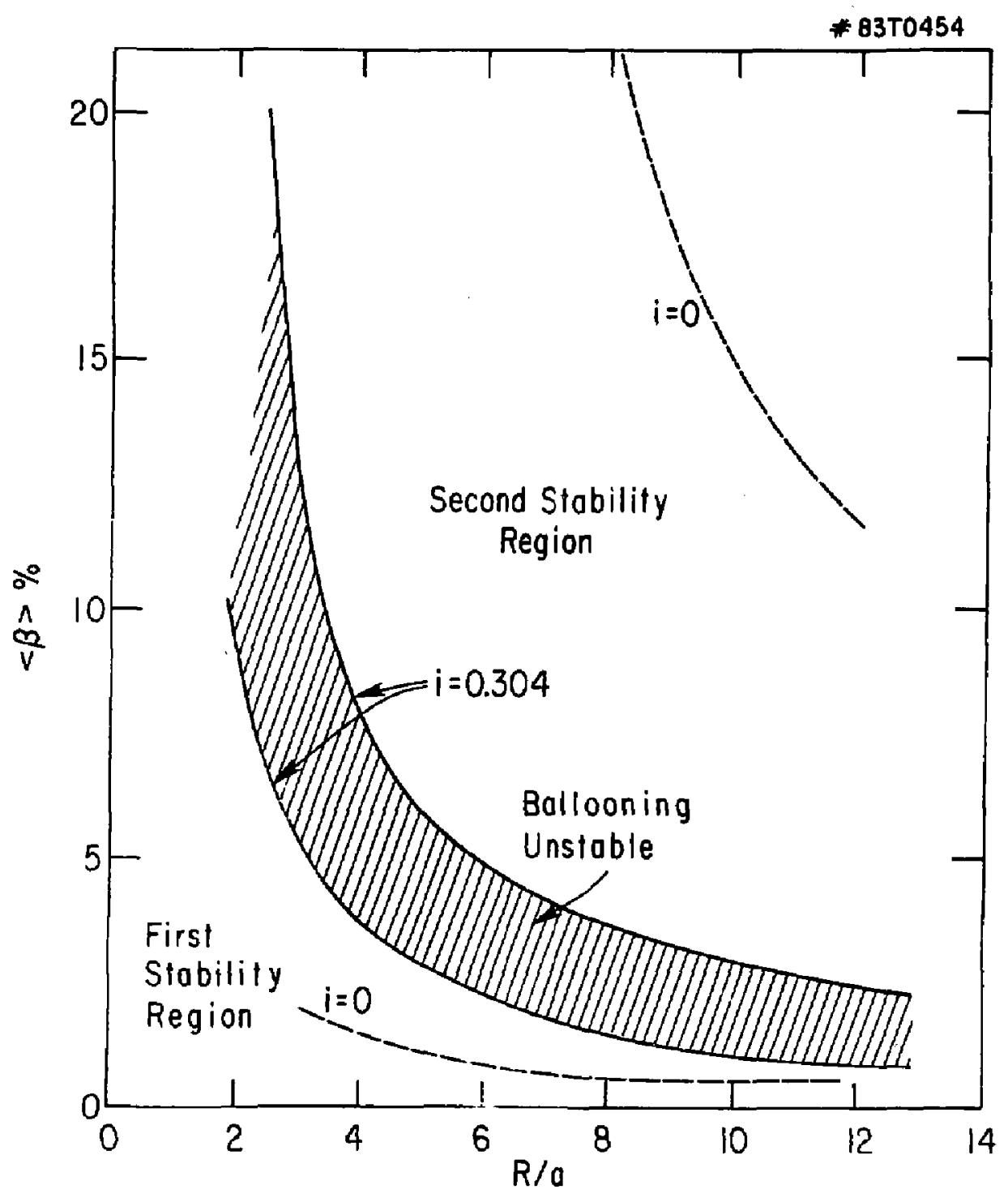

Fig. 5 


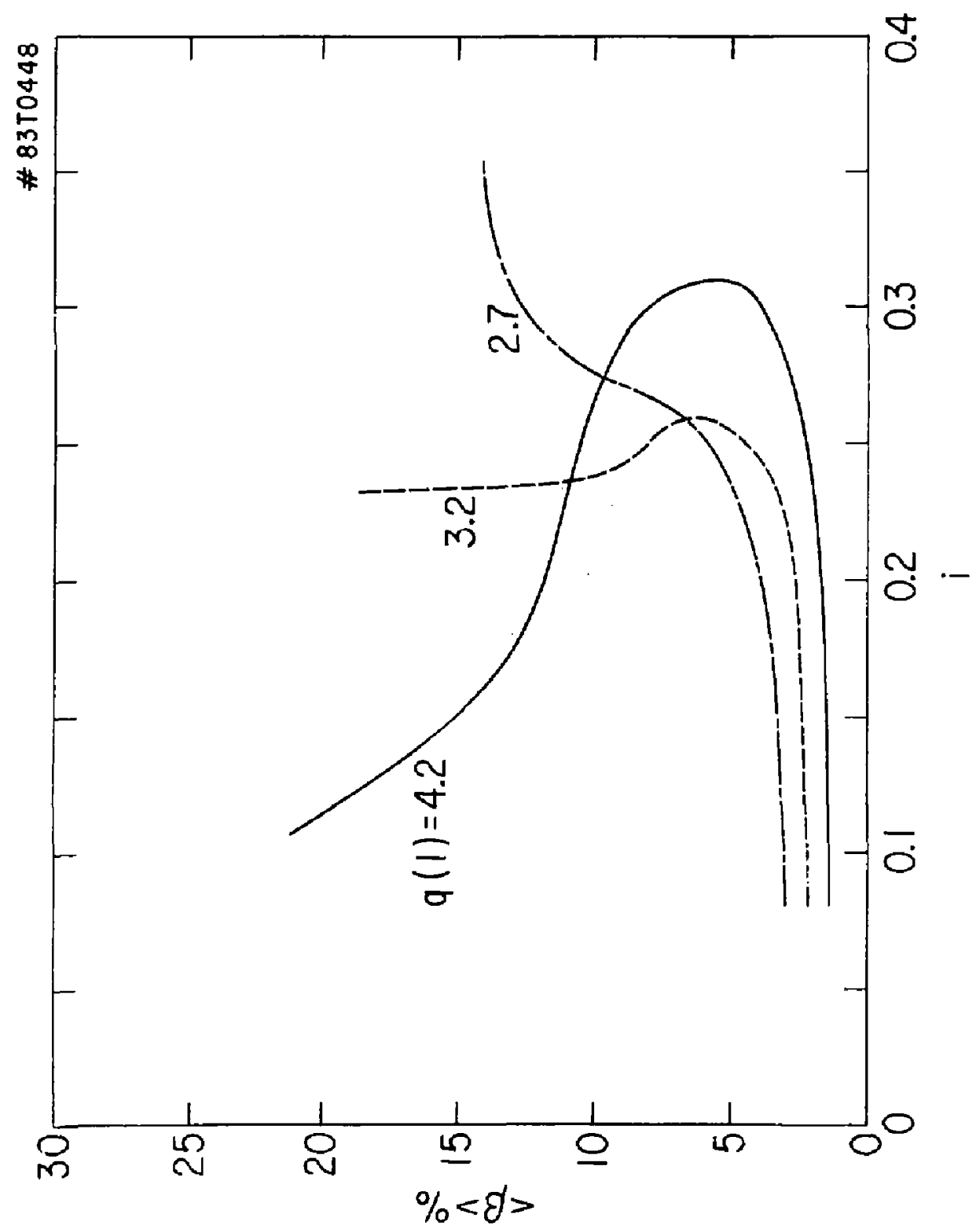

வ 


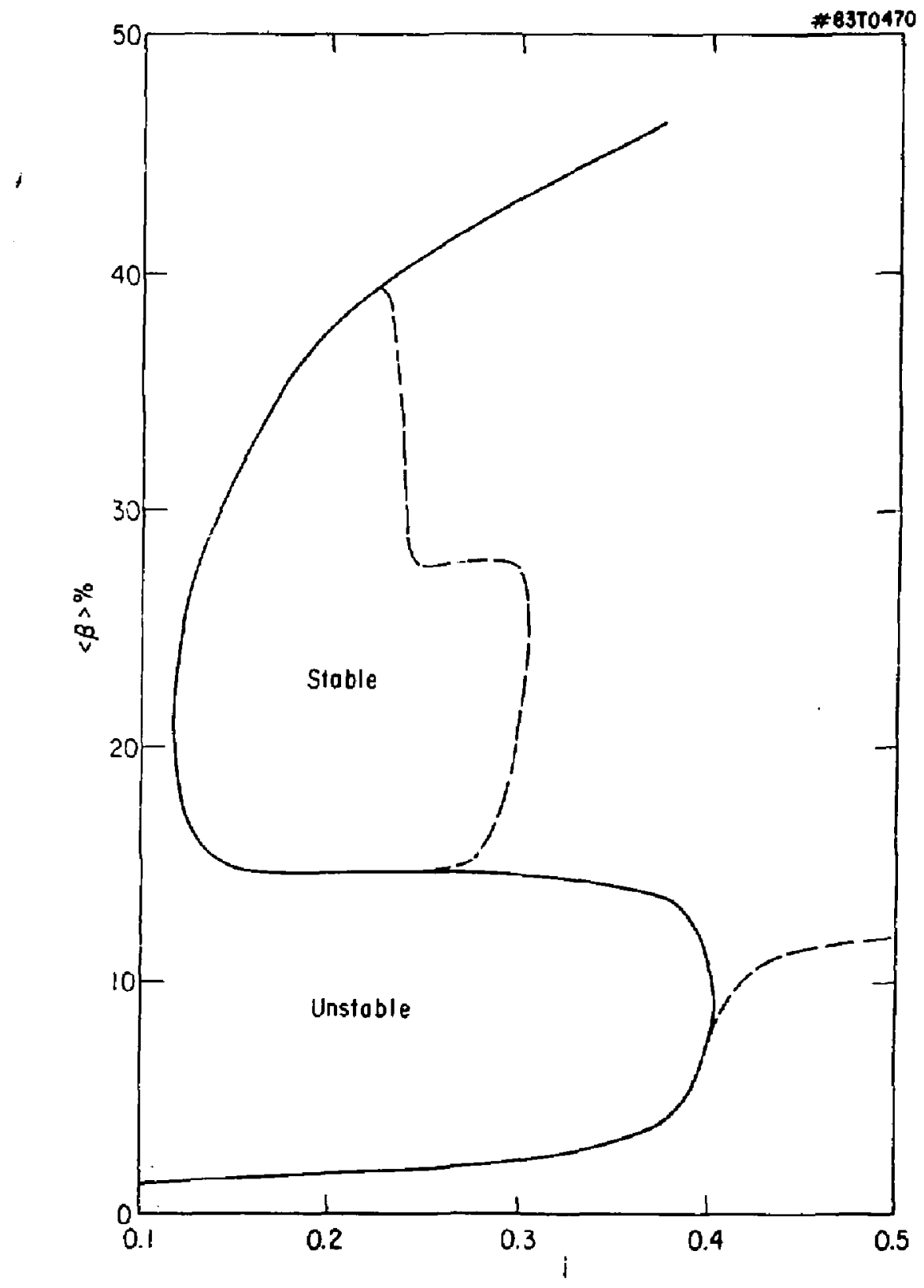

Fig. ? 


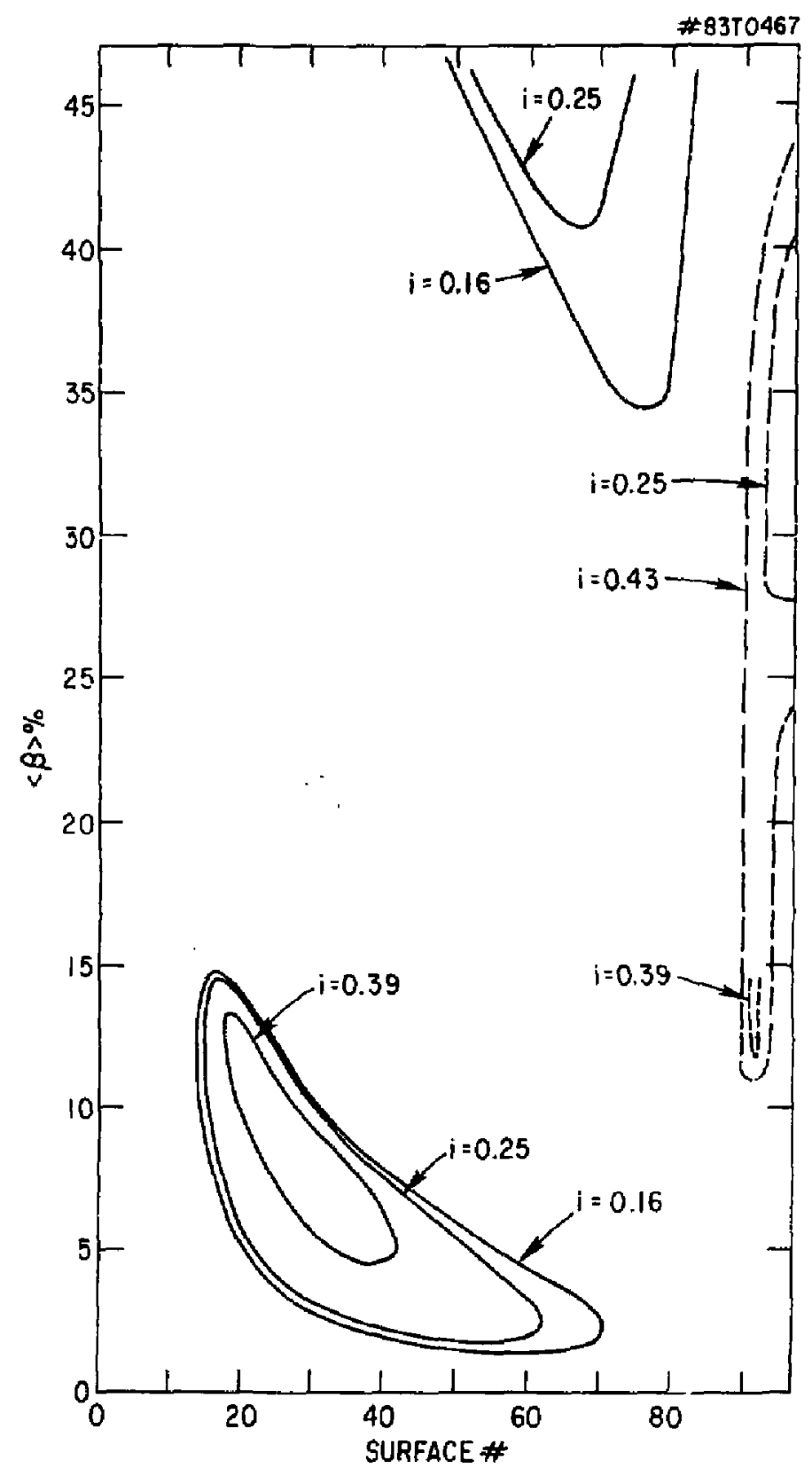

Fig. 8 


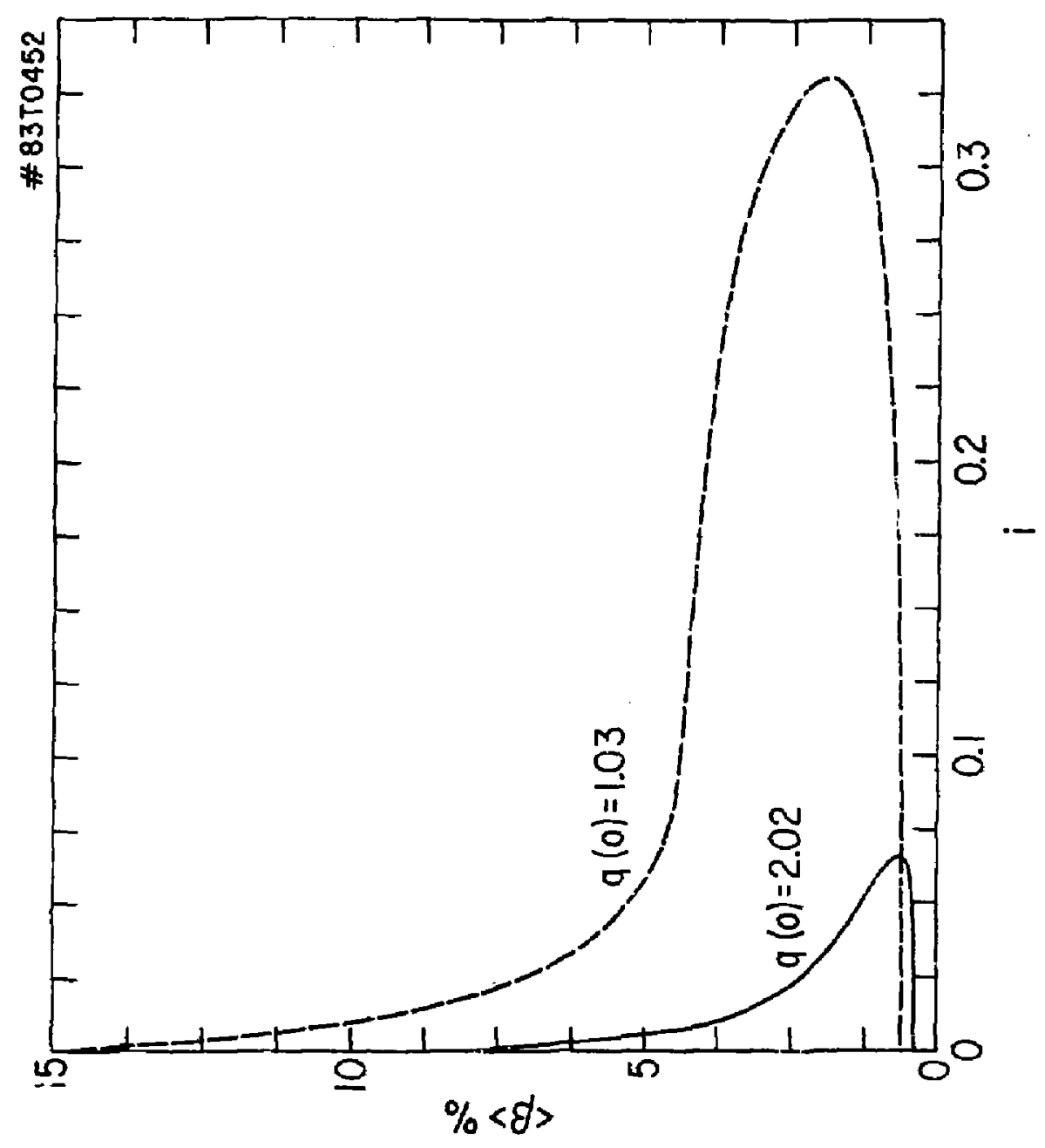

o 


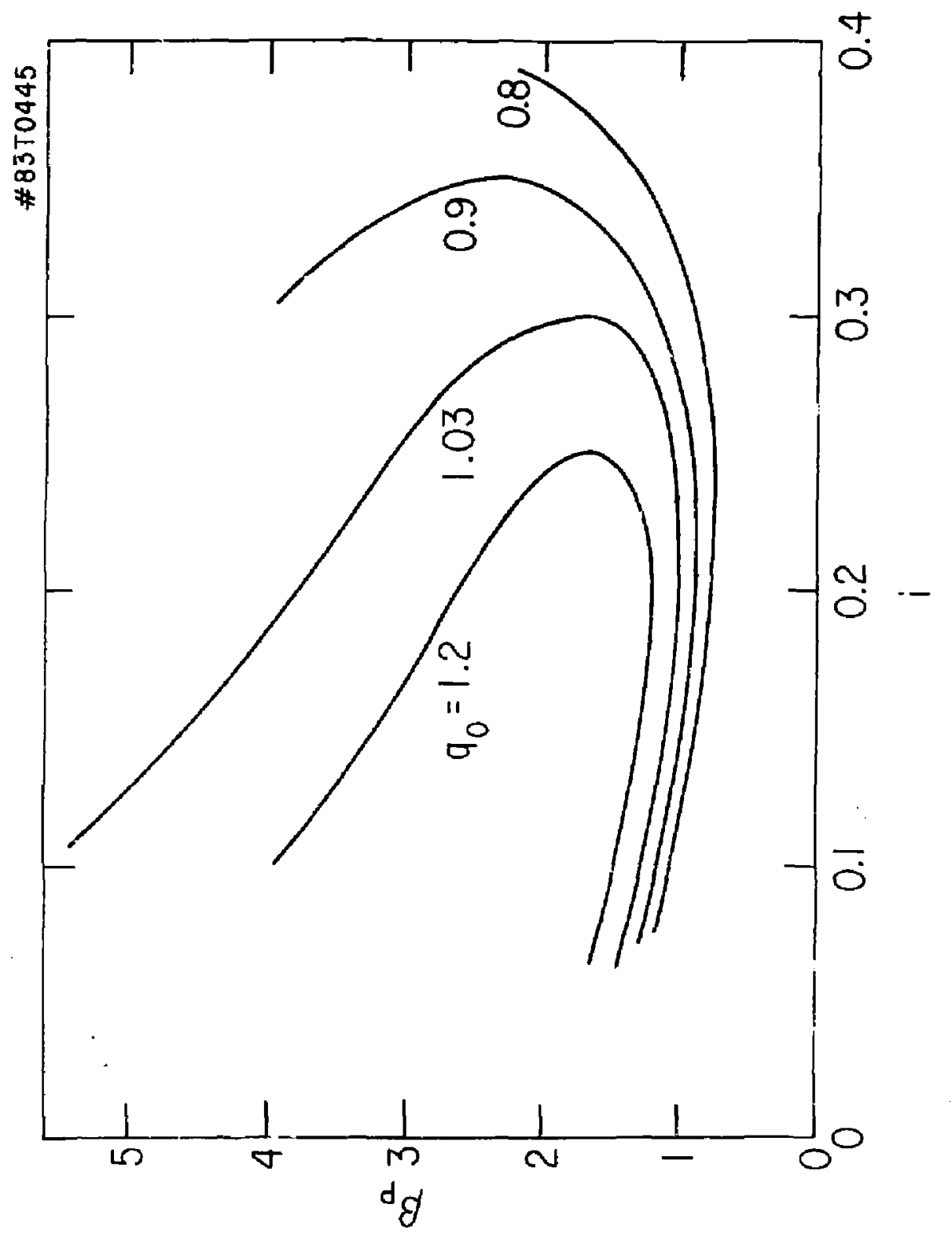

$\stackrel{0}{1}$
$\dot{9}$
$\dot{\omega}$ 


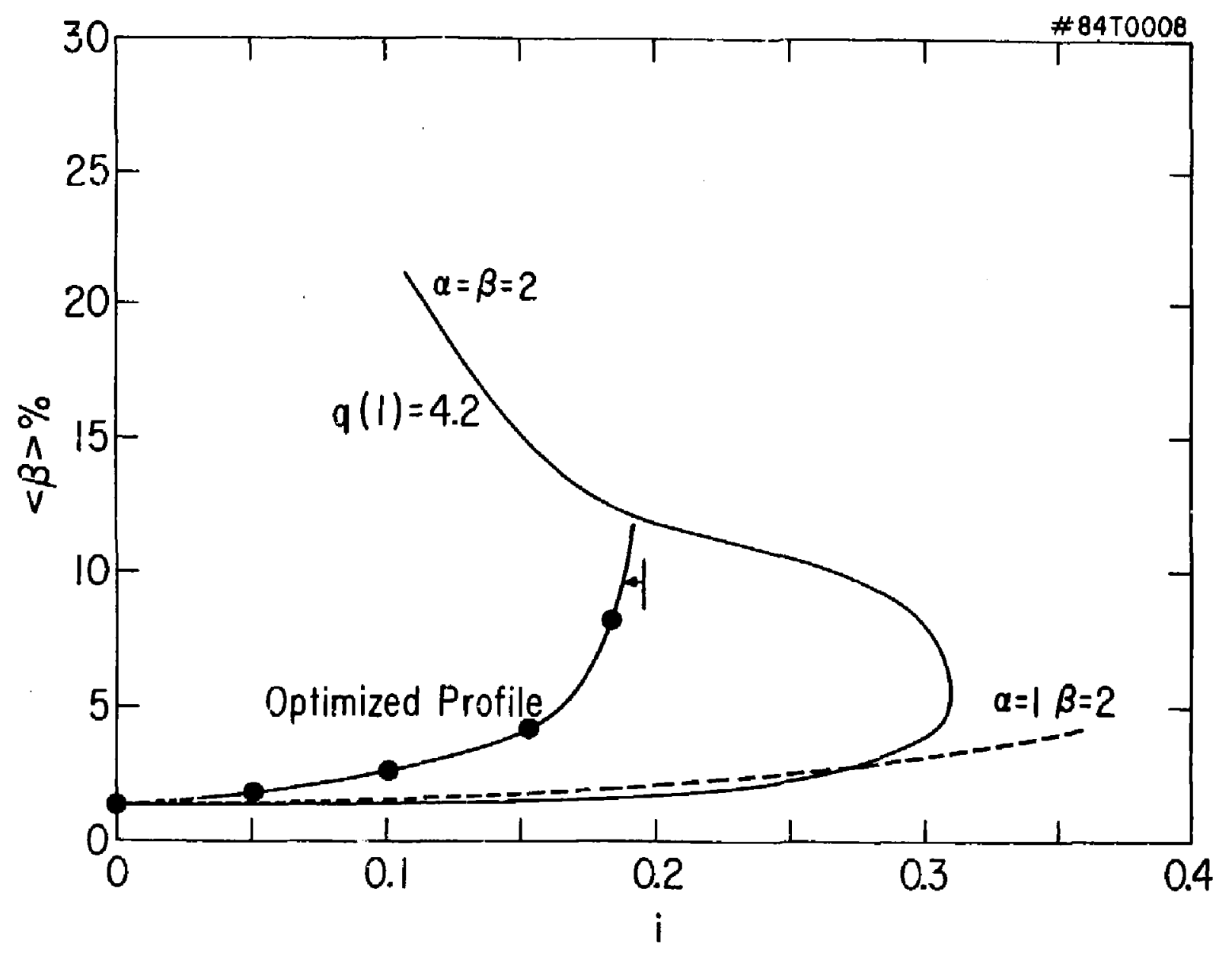




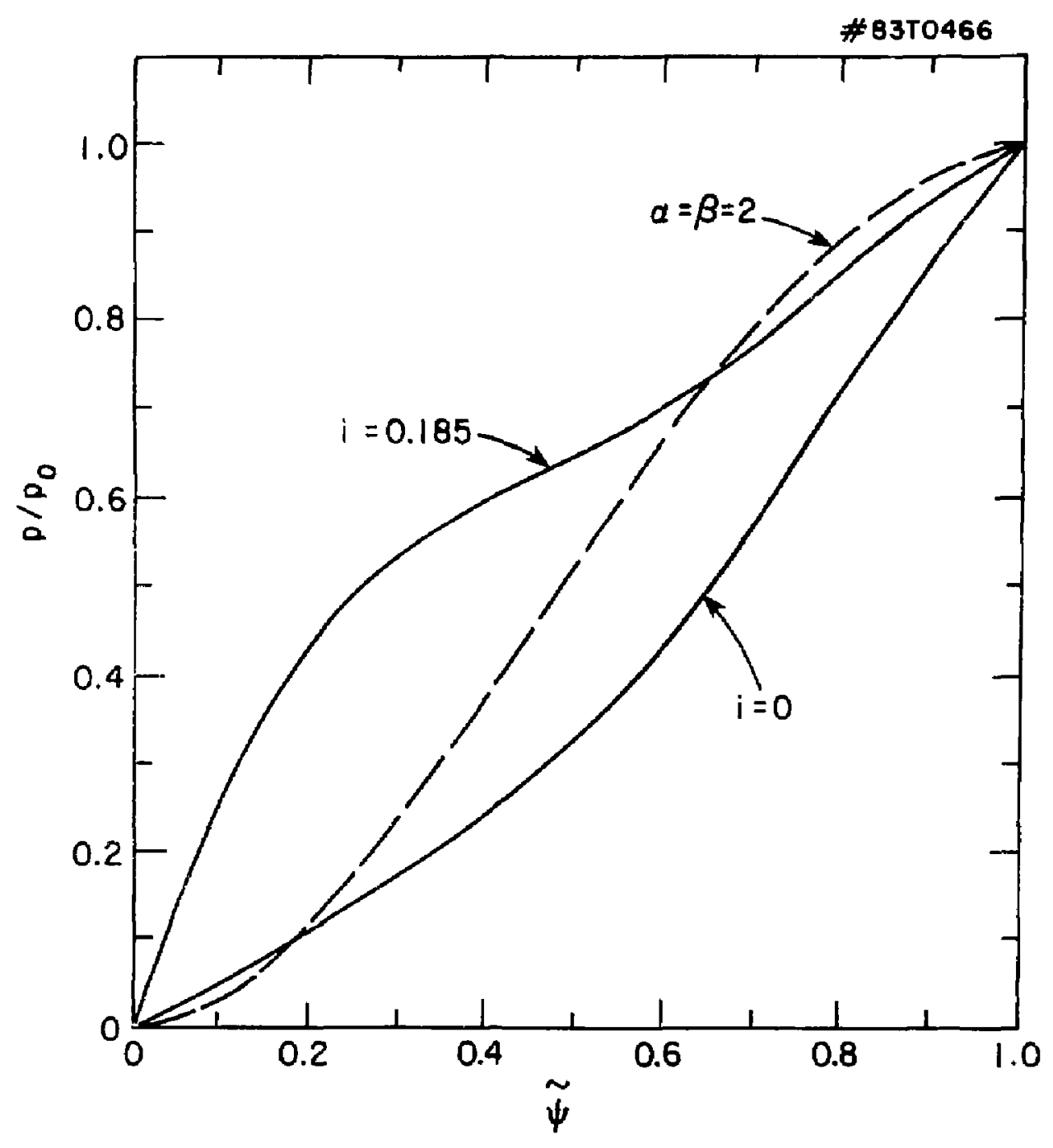

Fig. 12 


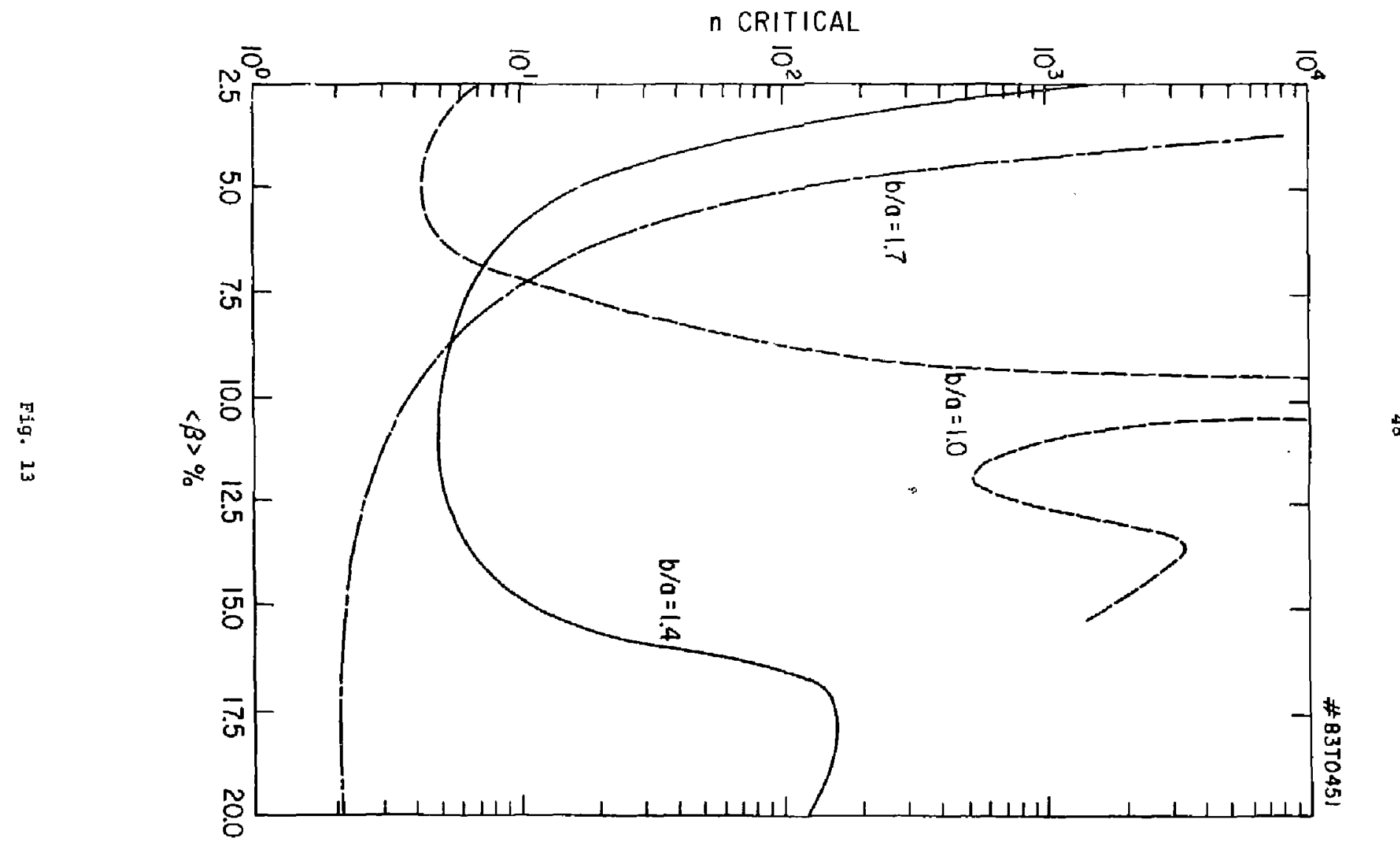




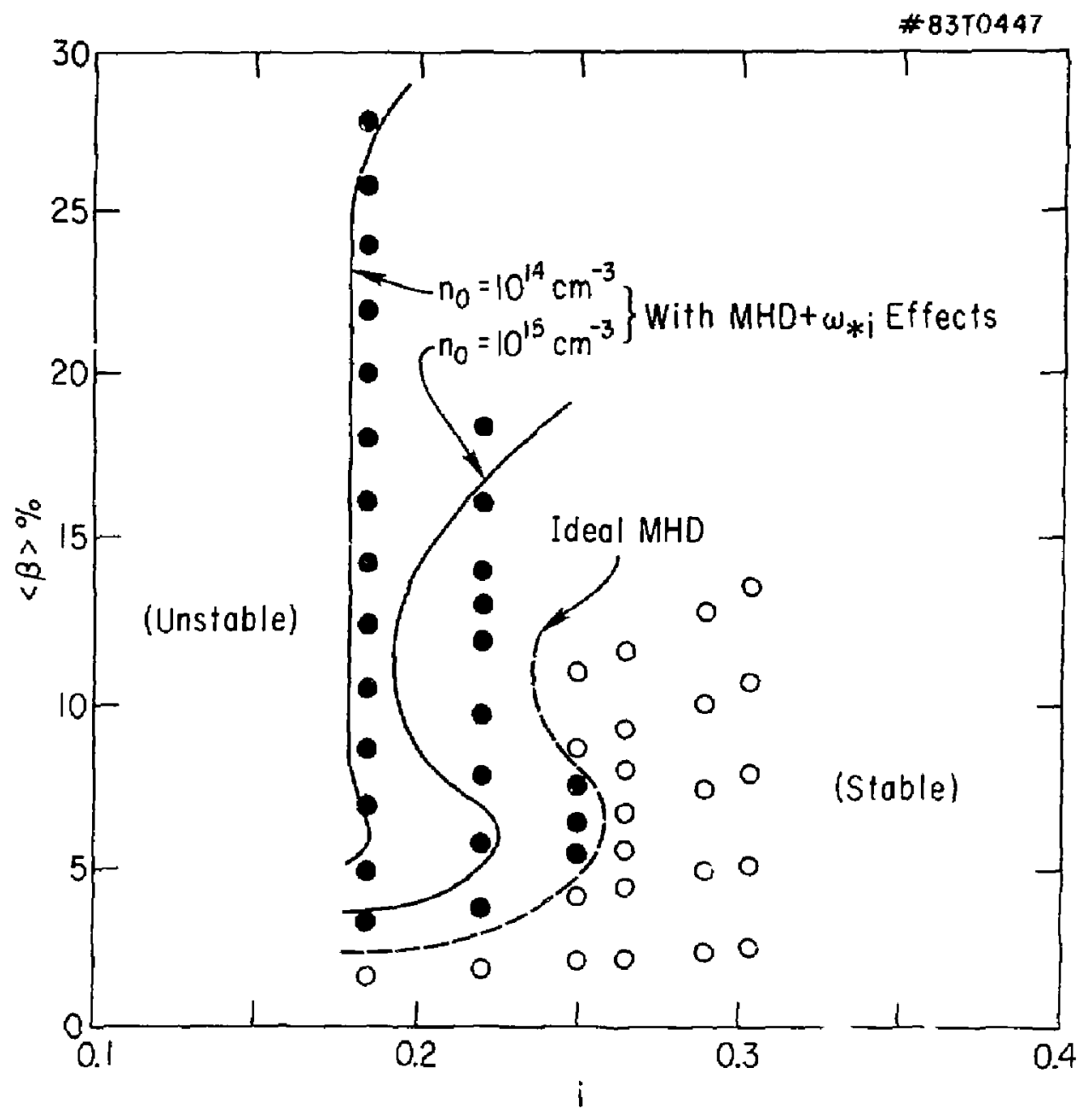

Fig. 14 


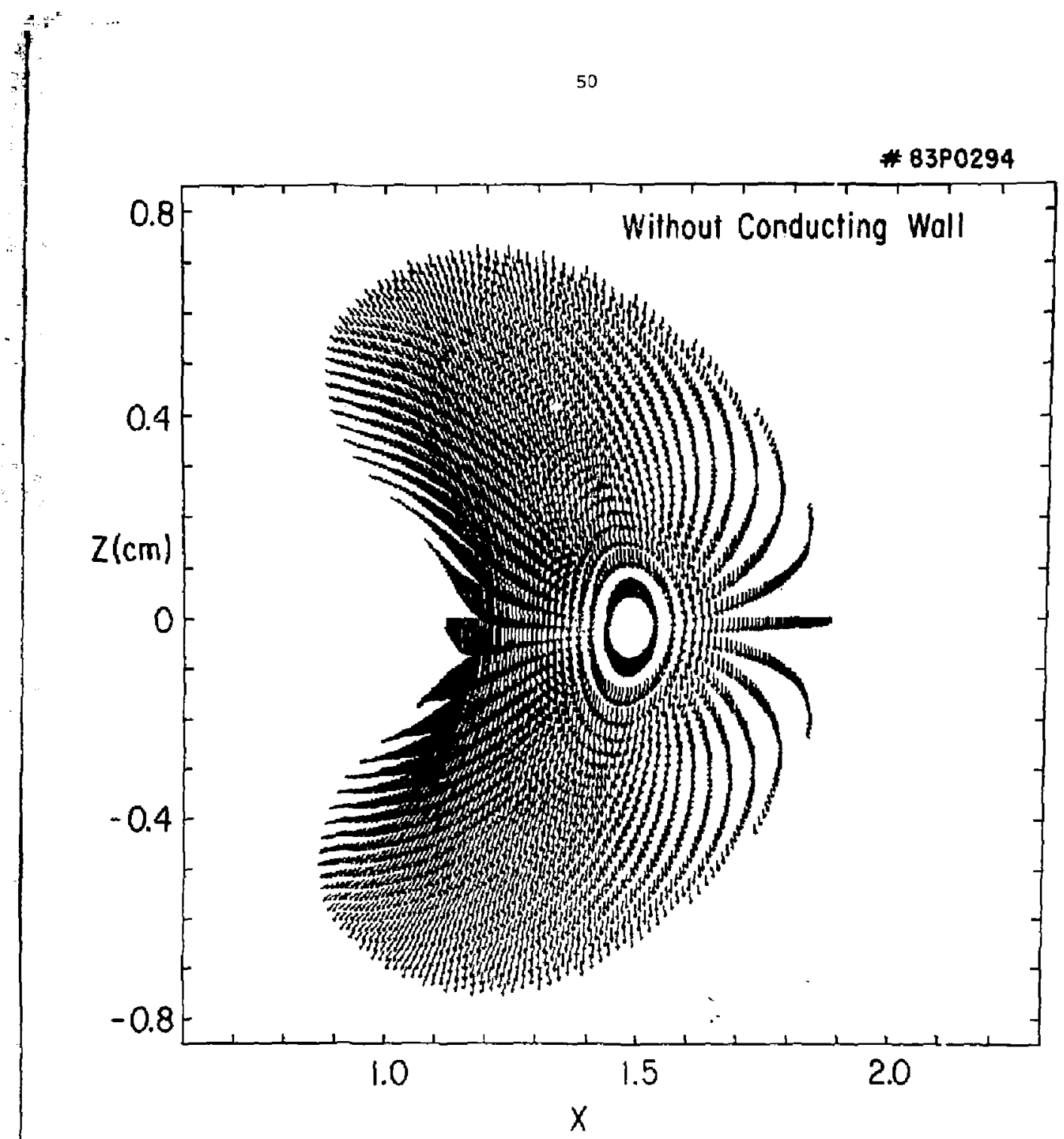

Fig. 15 
\#83P0293

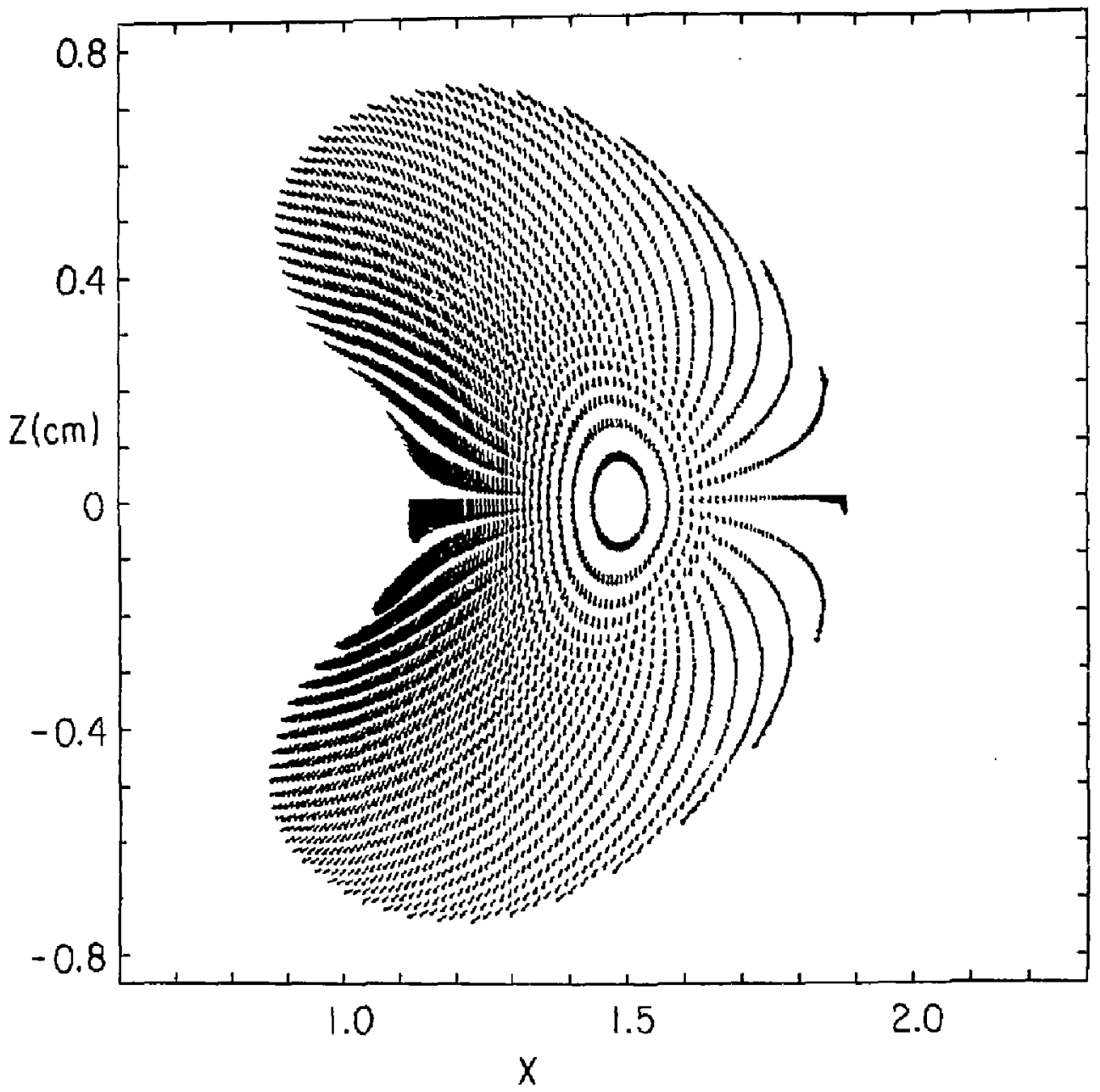

Fig. 16 

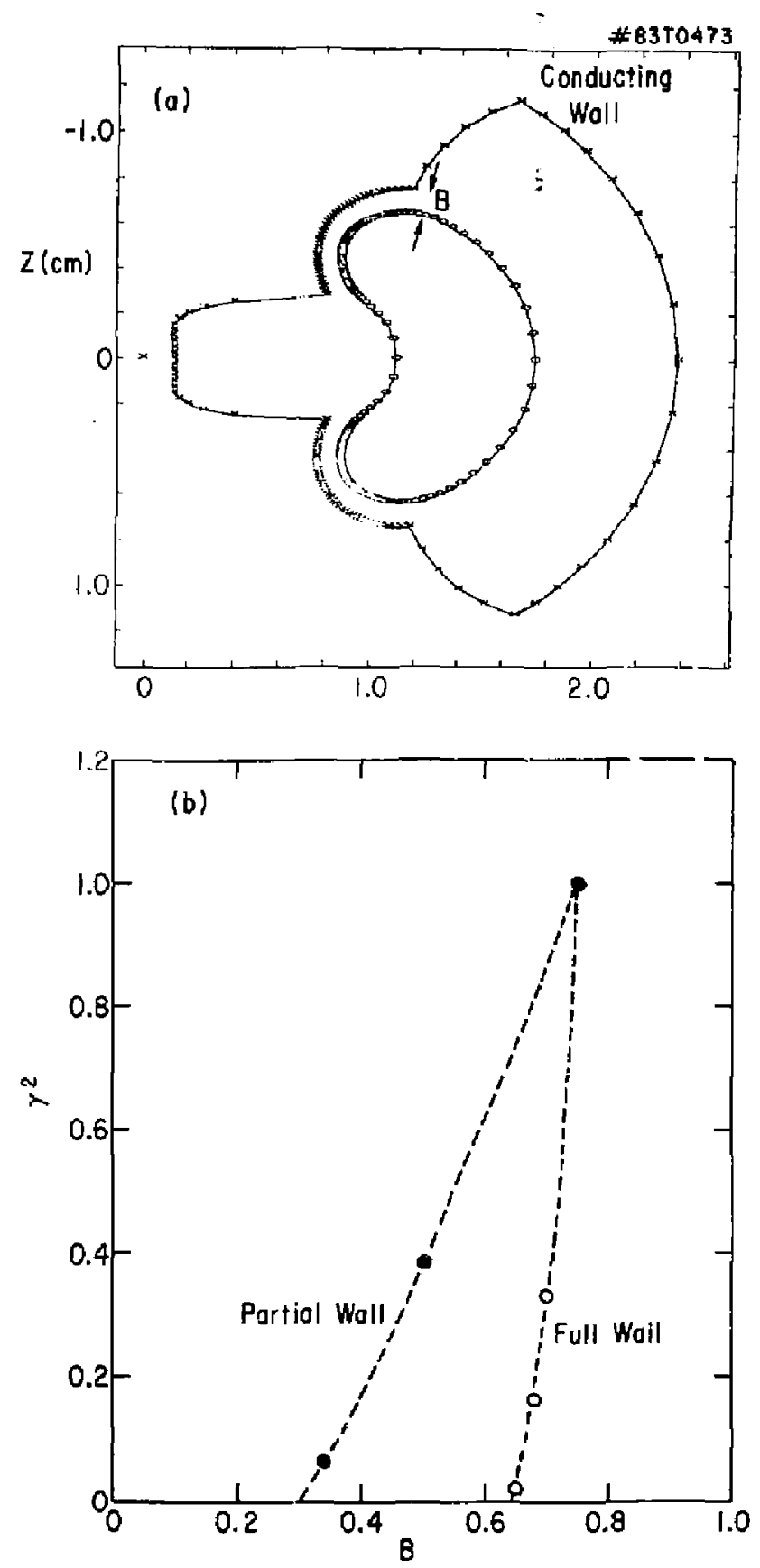

Fig. 17 


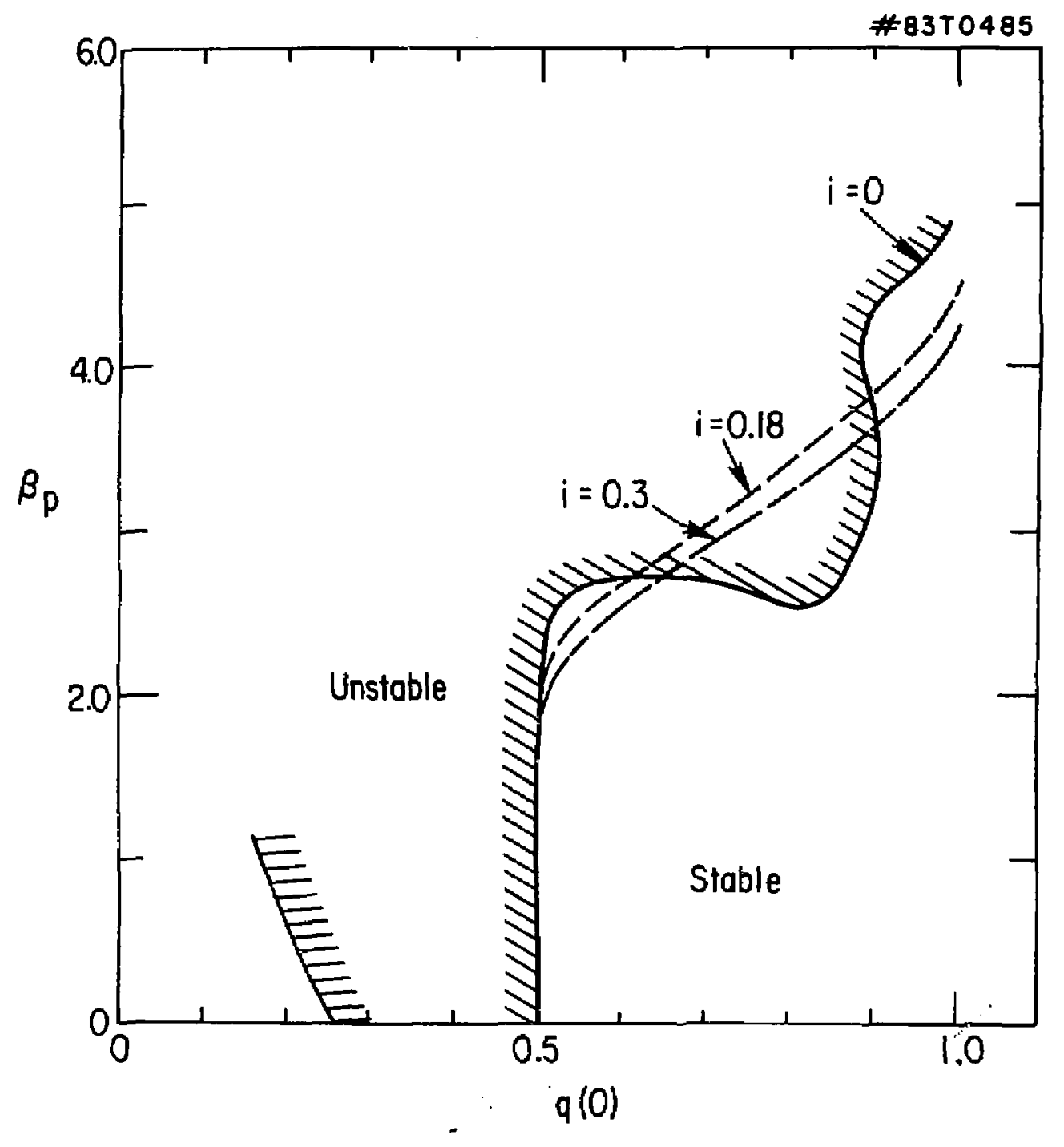

Fig. 18 


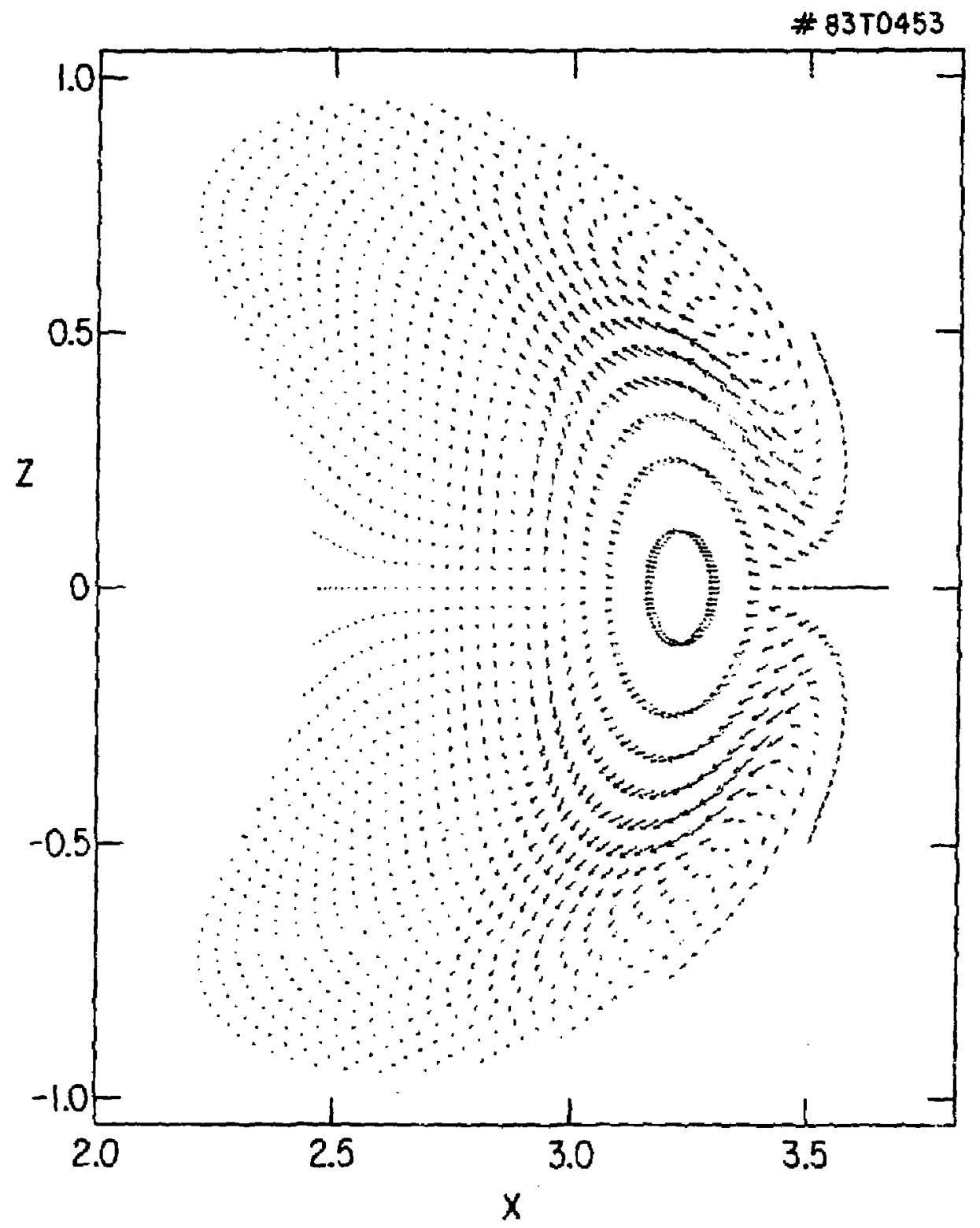

Fig. 19 


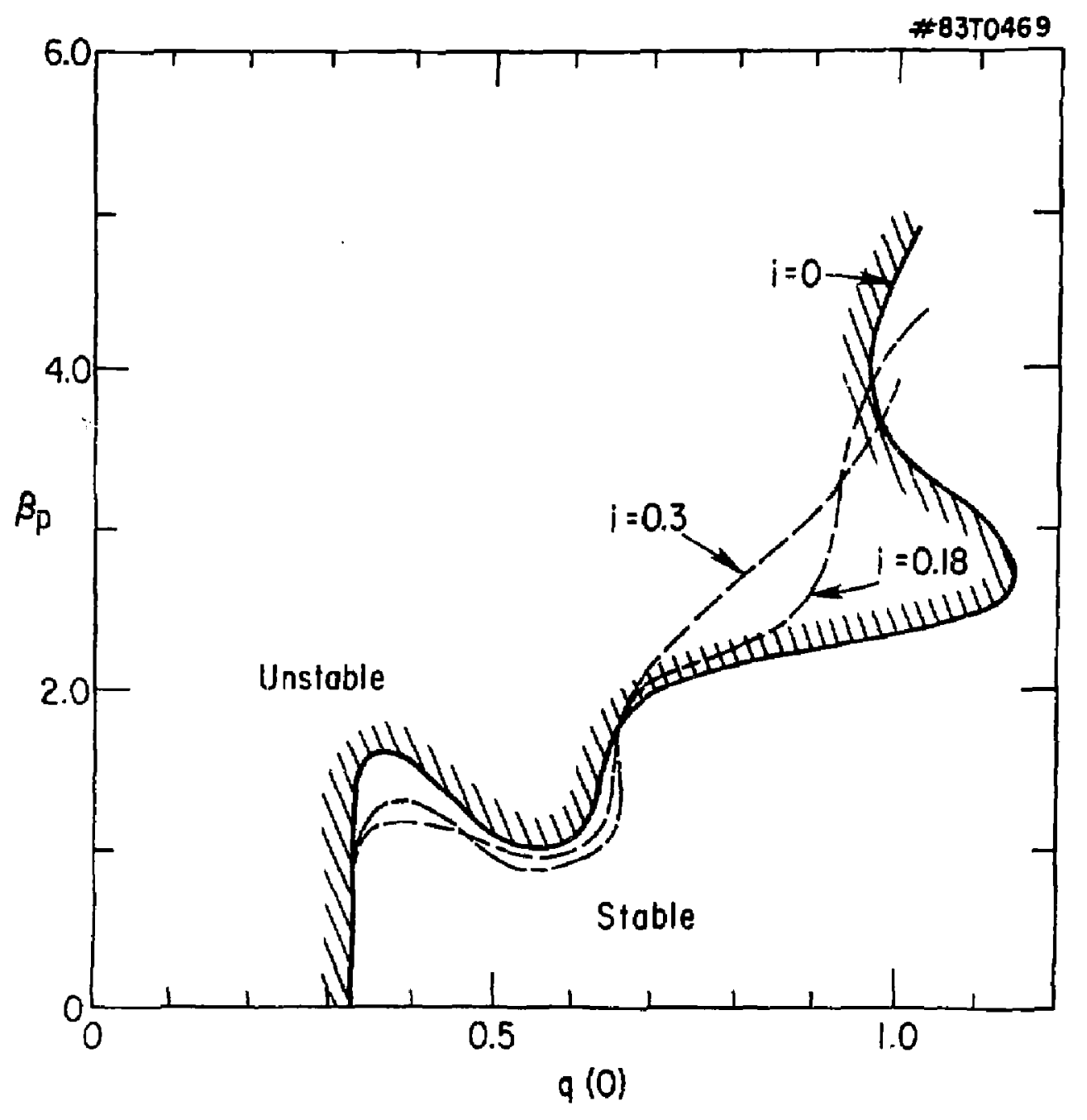

Fig. 20 



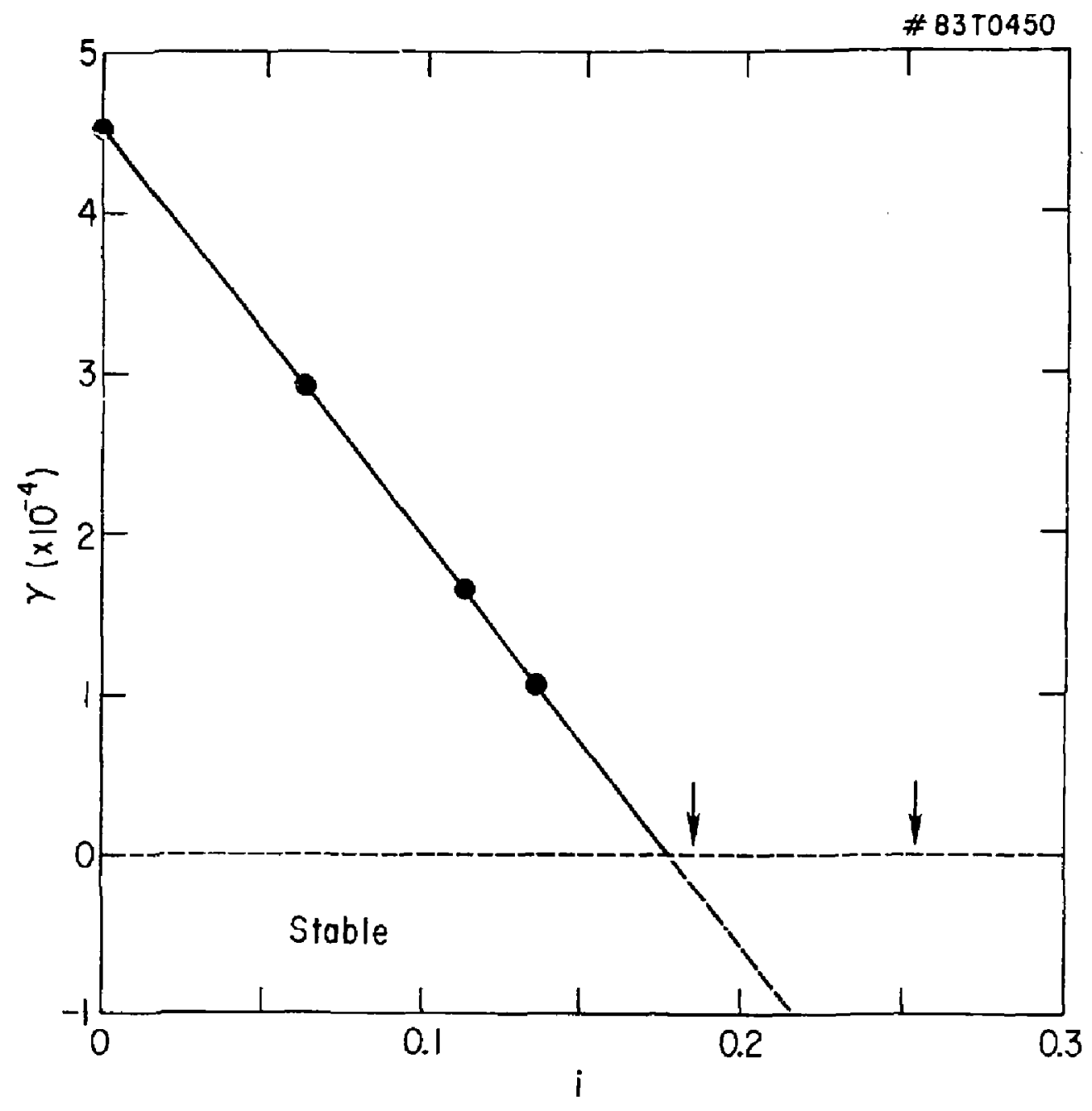

Fig. 22 


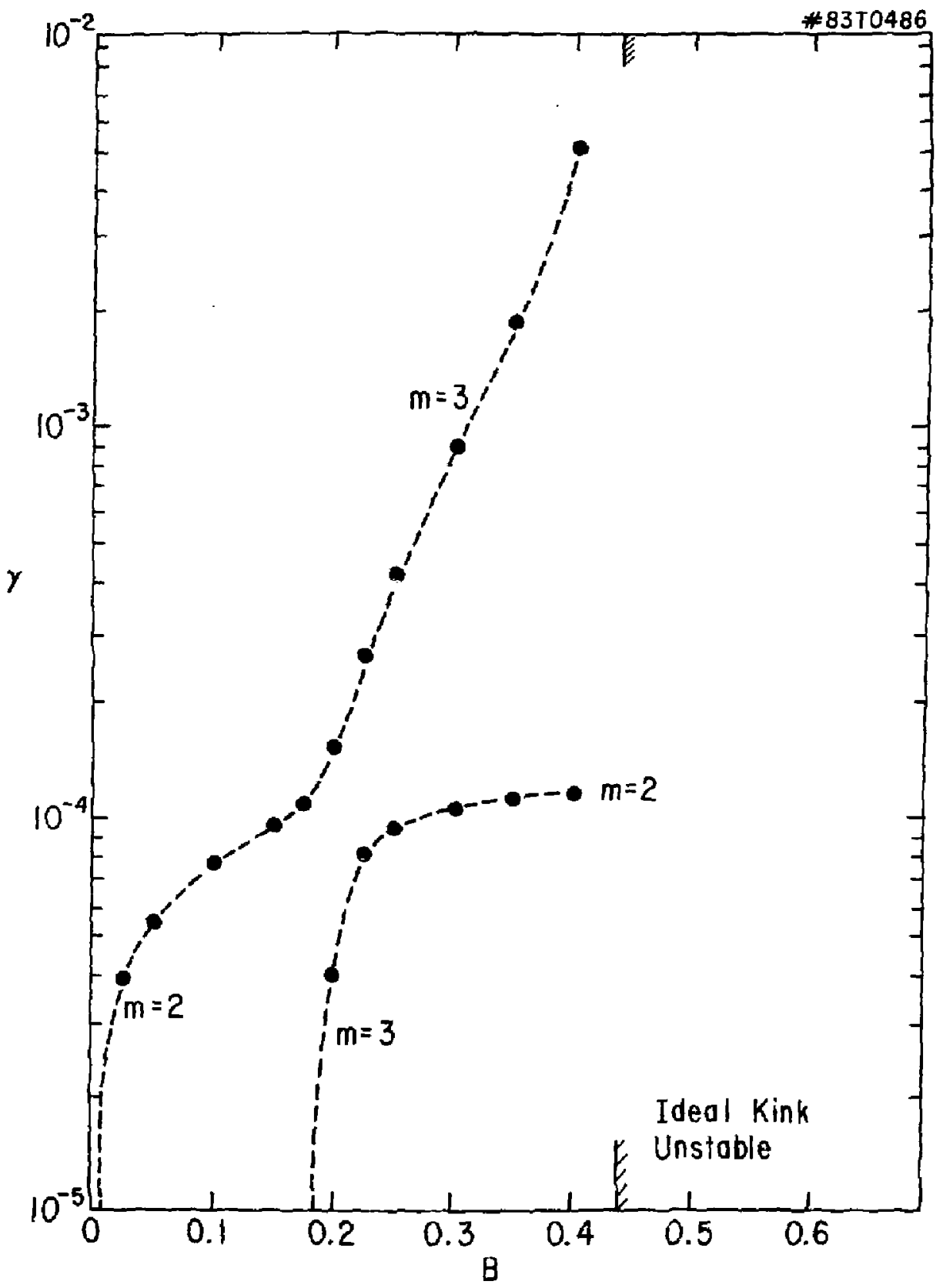

Fig. 23 
\# 83T0446

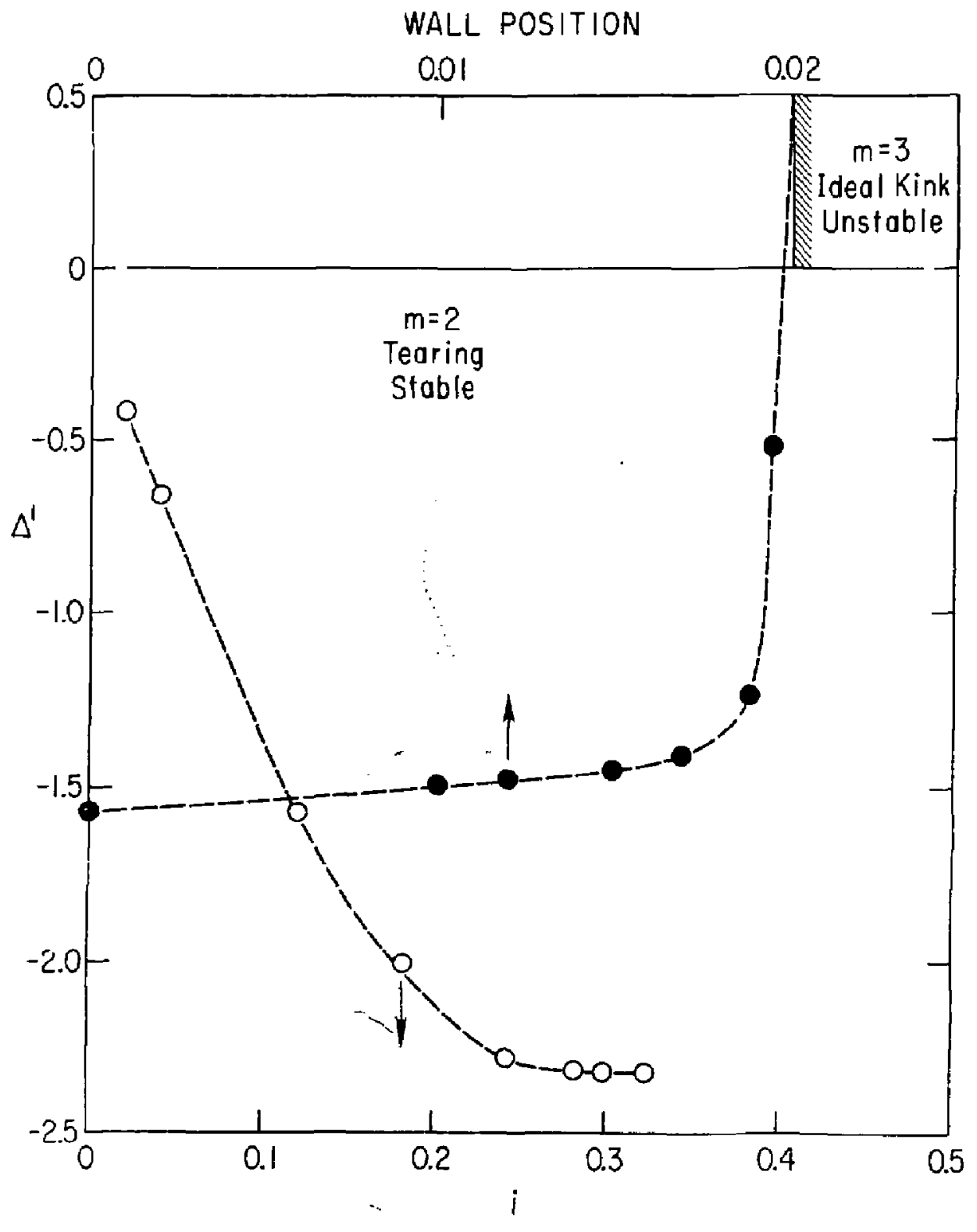

Fig. 24 


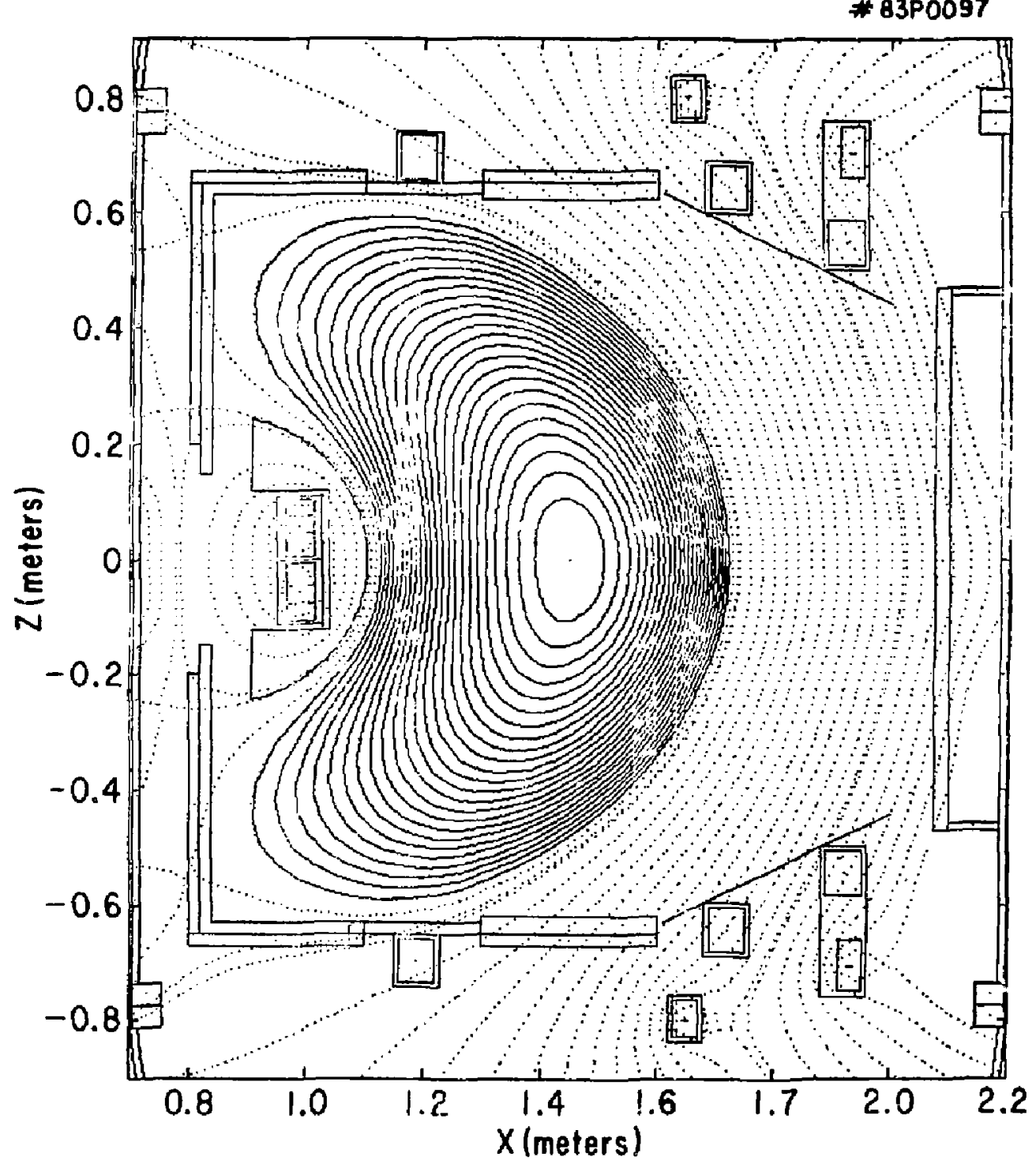

Fig. 25 
Plasmo Res Lob, Austro Nat'I Univ, AUSTRALIA Dr. Frank J. Pealonl, Uniy of Mollongong, AUSTRAL IA Prot, I,R. Jones, Flinders Unly.. AUSTRALIA Prot, M,H, Brennan. Unly Syóney, AUSTRALIh Prot. F. Cap, Inst Theo Phys, AuSTRIA Prot. Frank Verneest, Inst theoretische, BeLgilu Dr. D. Palumbo, Dg XII Fusion Prog, BeLGI UM Ecole Royde Milltaira, Lab de Phys Plasmes, BELGIuM Dr. P.H. Sakeriaka, Uniy Estadual, BRAzIL Dr. CR, Jemes, Univ of alberta, CANADA Prot, J. Telchmenn, Unlv of Montroal, CANADA Dr. H.M. Skersgord, Unlv of Saskbtcheran, CANADa Prot, S,R, Sreenlvasan. UnIverslty of Calgary, CAKADA Prof. Tudor W, Johnston, INR5-Energie, CANADA Dr. Hennes Barnard, Untr Britlsh Columbia, CANADA Dr. M.P. Bechynskl, MPQ Tochnologios, Inc., CANADA Zhengu LT, 5H Inst Physlcs, CHINK LIbrary, Tsing Huo University, CHIMA LIbrarlan, Institute of Physics, CHINA Inst Plasme Phys, Acadenta sinlco, CHINA Dr. Peter Lukac, Konenskeho Univ, CZECHOSLOVAKiA The Librarian, Culinem Laboretory, ENGLANO Prof. Schatzman, Observatolite de Nlce, FRance J. Rodet, CEN-SP6, FRANCE

AM Dupas Librory, AM Dupas Library, FRANCE Dr. Ton Muel. Acedeny Bl allographle. HONG KONG Proprint Library, Cont Ras Inst Phys, HUNGRRY Dr. S.K. Trehan, Panjad unlvorslty. India Or. Indre, Mohen Lal Des, Ganeras HIndu Univ, INDIA Dr. L.K, Chevdd, South Gujerat Untr, INDIA Dr. R.K. Chhajlani, Var Ruchl Marg, INOIA P. Kaw, Physlcal Rosearch Lab, INDIA Dr. Phillip Roseneu, 1srael inst Jech, ISRAEL Prof. 5. Cupormon, Tel Aviy Univers Ity, ISRAEL Prof. G. Rostogin l, Un Ir DI Padows, I TALY Llorarion, int'l Gtr Theo Phys, ITALY Miss Clello De Polo, Assoc EURATOM-CNEN, ITRLY BIbIlotecE, del CNR EURATOH, ITALY Dr. H. Yamoto, Toshlbo Res \& Dav, JAPAN Frof. M. Yoshlkaro, JAERI, Tokal Ros Est, JAPAN Frot. T. UehIdo, Universlty of Tokyo, JAPAN Research Info Center, Nagoya UnIversity, JAPAN Prot. KYoJI NIshJkawa, Univ of Klroshlme, JAPAN Prot. 5igeru Mori, JAERI, JAPAN LIbrary, Kyoto UnIvers ItY, JAPAN Prof. Ichlro Kowakeml, Nihan Univ, JAPAN Prot. Sotosh 1 Itoh, Kyushu UnIversity, JAPAN Tech Info Division, Korea Atoml c Energy, KOREA Dr. R. England, Cludad Unl versitaria, MEXICO Bibllathook, Fom-Inst Yoor Plosma, NETHERLANDS Prof. B.S. Liley, University of Walkato, NEW ZEALAND Dr. Surest C. Sharma, Univ of Calaber, NIGERIA
Prof. J,A,C. Cabral, Inst Superlor Toch, PORTuGaL Dr. Octavian Patrus, ALI CLeA UnI varsity, ROMNNIA Prot. M,A, Hel Ibarg, University of Hatal, SO AFRICA Dr. Johan de Villilers, atemle Enargy Bd, SO AFRiCA Fus lon Div. LI trary, JEN, SPAIN

Frof. Mans milnelmson, Chalners Jniv Toch, SWEDEN Dr. Lennart Stentlo, University of LMEA, SWEOEN LIbrary, Royai inst Tech, SWEDEN Or. ErIk T. Korlsan, Uppsala UnIvers ltet, SWEDEN Centre de Recherchesen, Ecole Polytech Fad, SultzerLaro Dr. W.L. WoIst, Nat'l Bur Stand, USA Dr. M.M. Stacey, Georg Inst Tech, USA Dr. S,T. Wu, Univ Alabens, USA Prof. Normon L. Oloson, UnIv S Floriod, LSA Dr. Banjanin Ma, lora State Univ, LSA Prof. Megne Kristiensen. Texas Toch Univ, USA Dr. Roymond Askew, Auburn Unlv, LSA Dr. V.T. Tolok, Kherkoy Phys Tech Ins, USSR Dr. D.D. Ryutov, SIberlan Acad Scl, USSR Dr, G,A, EIIsary, Kurchotor Institute, USSR Dr. V.A, Glukhlkh, Inst Electrofhyslcal, USSR Institute Gen, Physles, USSR

Prot. T.J. Boyd, Univ Col lege $N$ wa les, hales Dr. K. SehIndler, Ruhr Unlvarsleat, W. ERana Nuclear Res Estab, Jullch LTd, W. GEPMANY Librarian, Hax-Planck instltut, W. GERMANY Dr. H.d. Koopplar, UnIverslty Stuttgart, W, GERANY Bibllothek, Inst PI asmafor schung, W. GERANY 